
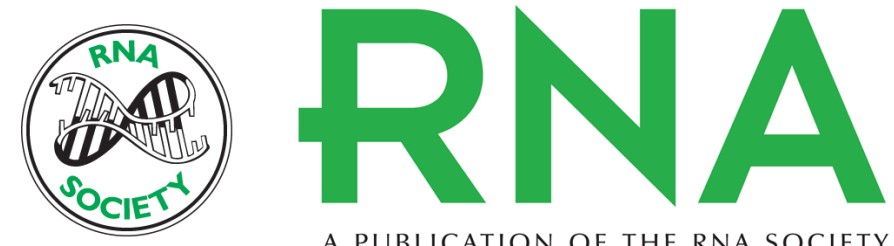

A PUBLICATION OF THE RNA SOCIETY

\title{
The C-terminal domain of TAP interacts with the nuclear pore complex and promotes export of specific CTE-bearing RNA substrates.
}

A Bachi, I C Braun, J P Rodrigues, et al.

RNA 2000 6: 136-158

Email Alerting Receive free email alerts when new articles cite this article - sign up in the box at the top Service right corner of the article or click here.

\section{Exiqon Grant Accelerate your RNA discoveries Program 2014 with a grant from Exiqon EXIQON}




\title{
The C-terminal domain of TAP interacts with the nuclear pore complex and promotes export of specific CTE-bearing RNA substrates
}

\author{
ANGELA BACHI, ${ }^{1 *}$ ISABELLE C. BRAUN, ${ }^{2,6 *}$ JOÃO P. RODRIGUES, ${ }^{3 *}$ NELLY PANTÉ,,${ }^{4 *}$ \\ KATHARINA RIBBECK, ${ }^{5}$ CAYETANO VON KOBBE, ${ }^{2}$ ULRIKE KUTAY, ${ }^{5}$ MATTHIAS WILM, ${ }^{1}$ \\ DIRK GÖRLICH, ${ }^{5}$ MARIA CARMO-FONSECA,${ }^{3}$ and ELISA IZAURRALDE ${ }^{2,6}$ \\ ${ }^{1}$ European Molecular Biology Laboratory, D-69117 Heidelberg, Germany \\ ${ }^{2}$ University of Geneva, Department of Molecular Biology, CH-1205 Geneva, Switzerland \\ ${ }^{3}$ Institute of Histology and Embryology, Faculty of Medicine, University of Lisbon, 1699 Lisboa Codex, Portugal \\ ${ }^{4}$ Institute of Biochemistry, Swiss Federal Institute of Technology (ETH), CH-8092 Zürich, Switzerland \\ ${ }^{5}$ Zentrum für Molekulare Biologie der Universität Heidelberg, 69120 Heidelberg, Germany
}

\begin{abstract}
Messenger RNAs are exported from the nucleus as large ribonucleoprotein complexes (mRNPs). To date, proteins implicated in this process include TAP/Mex67p and RAE1/Gle2p and are distinct from the nuclear transport receptors of the $\beta$-related, Ran-binding protein family. Mex67p is essential for mRNA export in yeast. Its vertebrate homolog TAP has been implicated in the export of cellular mRNAs and of simian type D viral RNAs bearing the constitutive transport element (CTE). Here we show that TAP is predominantly localized in the nucleoplasm and at both the nucleoplasmic and cytoplasmic faces of the nuclear pore complex (NPC). TAP interacts with multiple components of the NPC including the nucleoporins CAN, Nup98, Nup153, p62, and with three major NPC subcomplexes. The nucleoporinbinding domain of TAP comprises residues 508-619. In HeLa cells, this domain is necessary and sufficient to target GFP-TAP fusions to the nuclear rim. Moreover, the isolated domain strongly competes multiple export pathways in vivo, probably by blocking binding sites on the NPC that are shared with other transport receptors. Microinjection experiments implicate this domain in the export of specific CTE-containing RNAs. Finally, we show that TAP interacts with transportin and with two proteins implicated in the export of cellular mRNAs: RAE1/hGle2 and E1B-AP5. The interaction of TAP with nucleoporins, its direct binding to the CTE RNA, and its association with two mRNP binding proteins suggest that TAP is an RNA export mediator that may bridge the interaction between specific RNP export substrates and the NPC.
\end{abstract}

Keywords: CTE; mRNA export; nucleoporins; nuclear export; TAP

\section{INTRODUCTION}

Nuclear transport occurs through the nuclear pore complexes (NPC) and depends on the presence of nuclear localization signals (NLSs) or nuclear export signals (NESs) in the transported molecules. NLSs or NESs are recognized and bound by saturable import or export receptors that shuttle between the nucleus and

Reprint requests to: Elisa Izaurralde, European Molecular Biology Laboratory, Meyerhofstrasse 1, D-69117 Heidelberg, Germany; e-mail: izaurralde@embl-heidelberg.de.

*These authors contributed equally to this work.

${ }^{6}$ Present address: European Molecular Biology Laboratory, Meyerhofstrasse 1, D-69117 Heidelberg, Germany.

Abbreviations: CTE: constitutive transport element; FG-repeats: phenylalanine-glycine dipeptide repeats; NPC: nuclear pore complex; SRV-1: simian retrovirus-1. cytoplasm. Upon binding, the transport receptors dock their cargoes to the NPC and facilitate their translocation. After delivering their cargoes, the receptors are recycled to initiate additional rounds of transport (reviewed by Görlich, 1997; Nakielny \& Dreyfuss, 1997; Mattaj \& Englmeier, 1998). A key regulator of nucleocytoplasmic transport is the small GTPase Ran (reviewed by Görlich, 1997; Dahlberg \& Lund, 1998; Mattaj \& Englmeier, 1998). Ran exists in a GTP- or GDPbound form. The location of RanGAP1 primarily in the cytoplasm and RanGEF in the nucleus is believed to generate a nucleocytoplasmic gradient of RanGTP across the NPC that imparts directionality to the transport process (Görlich et al., 1996; Izaurralde et al., 1997; Richards et al., 1997). Additional Ran cofactors are the Ran-binding protein 1 (RanBP1), which costimulates the activity of RanGAP1 (Bischoff et al., 1995a, 1995b), 
and the Ran-binding protein 2 (RanBP2/Nup358) (Wu et al., 1995; Yokoyoma et al., 1995), which may have, in part, a similar function to RanBP1. RanBP2/Nup358 is localized to the cytoplasmic fibrils of the NPC (Wu et al., 1995; Yokoyoma et al., 1995), whereas RanBP1 is predominantly cytoplasmic (reviewed by Görlich, 1997; Mattaj \& Englmeier, 1998). A fraction of RanGAP1 conjugated with the ubiquitin-like molecule SUMO-1, binds to RanBP2 and localizes to the cytoplasmic fibrils of the NPC (Matunis et al., 1996; Mahajan et al., 1997; Saitoh et al., 1997).

Transport receptors identified to date are members of a large family of RanGTP-binding proteins exhibiting limited sequence similarity with the Ran-binding domain of importin- $\beta$ (Görlich et al., 1997; Fornerod et al., 1997b), and have been termed importins/exportins or karyopherins. The interaction of these $\beta$-related receptors with their cargoes or with nucleoporins is regulated by the binding of Ran to the receptor (reviewed by Mattaj \& Englmeier, 1998). During export, the binding of RanGTP to the receptor is required for interaction of the receptor with its cargo and probably for the binding of the receptor to the pore. The opposite situation exists during import: free nuclear RanGTP is thought to trigger the release of the cargo on the nucleoplasmic side of the pore after translocation.

One of the best characterized nuclear export receptors is CRM1 (Fornerod et al., 1997a; Fukuda et al., 1997; Stade et al., 1997). CRM1 recognizes short leucine-rich sequences known as leucine-rich NESs or Rev-like NESs, as this type of NES was first described in the HIV Rev protein (Fischer et al., 1995). CRM1 was also shown to bind to more complex NES sequences such as the one present in snurportin-1 (Paraskeva et al., 1999), and to be involved in the export of one class of cellular RNAs, the spliceosomal uracil-rich small nuclear RNAs (U snRNAs) (Fornerod et al., 1997a). CRM1 interacts with several FG-repeat-containing nucleoporins (Neville et al., 1997) including CAN (Fornerod et al., 1997b; Askjaer et al., 1999; Kehlenbach et al., 1999), Nup153 (Nakielny et al., 1999) and Nup98 (Zolotukhin \& Felber, 1999). As for all members of the Ran-binding protein family, CRM1 binding to its substrate and to nucleoporins is regulated by Ran (Fornerod et al., 1997a; Askjaer et al., 1999; Kehlenbach et al., 1999; Nakielny et al., 1999; Paraskeva et al., 1999).

The search for factors implicated in mRNA export has led to the identification of several nucleoporins and NPC-associated proteins in yeast. Although some nucleoporins may play an indirect role in nuclear export as structural elements of the NPC, a direct role of some yeast nucleoporins in mRNA export has been suggested by the existence of conditional mutants that readily accumulate polyadenylated RNAs in the nucleus following a shift to the nonpermissive temperature (reviewed by Doye \& Hurt, 1997). Aside from the bona fide nucleoporins, the yeast proteins Gle2p/Rae1p
(Brown et al., 1995; Murphy et al., 1996; Bailer et al., 1998) and Mex67p (Segref et al., 1997; Santos-Rosa et al., 1998) are particularly good candidates for proteins that play a direct role in mRNA nuclear export. First, conditional mutants of these proteins lead to a rapid accumulation of polyadenylated RNAs in the nucleus at the nonpermissive temperature, without affecting protein import. Second, although a fraction of these proteins colocalize with NPC markers, a soluble fraction is also found in the nuclear and cytoplasmic compartments, suggesting that these proteins may transiently bind to the NPC during the transport process (Doye \& Hurt, 1997). Gle2p directly interacts with the nucleoporin Nup116p (Bailer et al., 1998) whereas Mex67p requires Mtr2p for stable association with the nuclear pores (Santos-Rosa et al., 1998). The vertebrate homologs of Gle2p and Mex67p, hGle2 (hRAE1/ mRNP41) and TAP (Bharathi et al., 1997; Kraemer \& Blobel, 1997; Segref et al., 1997) have been implicated in the nuclear export of cellular mRNAs (Grüter et al., 1998; Katahira et al., 1999; Pritchard et al., 1999).

Previously we have identified TAP as the cellular factor that is recruited by the constitutive transport element (CTE) of simian type $D$ retroviruses to promote nuclear export of their genomic RNA (Grüter et al., 1998; Braun et al., 1999). TAP binds directly to the CTE RNA via an N-terminal domain comprising residues 61-372 (Braun et al., 1999; Kang \& Cullen, 1999). In Xenopus oocytes this domain is necessary and sufficient to stimulate the nuclear exit of excised intron lariats bearing the CTE (Braun et al., 1999). In contrast, in avian and Xenopus cultured cells, the CTE-binding domain is not sufficient to mediate CTE-dependent export of an unspliced precursor mRNA as residues located at the $\mathrm{C}$-terminus of the protein are also required for this function (Bear et al., 1999; Kang \& Cullen, 1999). The mechanism by which TAP mediates the nuclear export of cellular mRNAs and of CTE-bearing RNAs remains to be established.

Here we show that the C-terminal domain of TAP mediates CTE-dependent export of specific RNA substrates. This C-terminal domain (residues 508-619) interacts with the FG-repeat domains of multiple nucleoporins and represents the NPC-targeting domain of TAP. Indeed, in vivo this domain is required for the localization of TAP to the nuclear rim. Moreover, the isolated NPC-binding domain of TAP inhibits RRE- and CTE-dependent nuclear export and the nuclear exit of mRNA and $U$ snRNA. These findings suggest that in vivo this domain competes with mediators of these various transport substrates for binding sites at the NPC. Finally, transportin (Pollard et al., 1997) and two mRNA-associated proteins, hGle2 (Kraemer \& Blobel, 1997; Bharathi et al., 1997; Pritchard et al., 1999) and E1B-AP5 (Gabler et al., 1998), previously implicated in mRNA export, were also identified as putative TAP partners. 


\section{RESULTS}

\section{The C-terminal domain of TAP promotes nuclear export of specific RNA substrates}

A role of the C-terminal domain of TAP in the export of CTE-containing pre-mRNAs was demonstrated in avian and Xenopus cultured cells whereas in Xenopus oocytes this domain was not required to promote CTEdependent export of an excised intron lariat (see Introduction). Therefore we hypothesized that the $\mathrm{C}$-terminal domain of TAP may be required as a function of the nuclear retention mechanisms that need to be bypassed by TAP/CTE complexes to promote export of specific RNA substrates. To test this hypothesis we compared the domains of TAP required to stimulate CTE-dependent export of an excised intron lariat or of U6 RNA by microinjection in Xenopus oocytes. The mechanism by which U6 RNA is retained in the nucleus remains largely unknown but it is likely to differ from those that sequester intron lariats or unprocessed premRNAs (Boelens et al., 1995). Xenopus oocyte nuclei were injected with a mixture of labeled RNAs consisting of an adenovirus-derived precursor mRNA bearing the wild-type SRV-1 CTE in the intron (Saavedra et al., 1997), U6 6 ss RNA and U1 1 Sm RNA. U6 6 ss RNA is not exported from the nucleus and lacks protein-binding sites required for nuclear import; it therefore remains at the site of injection and serves as an internal control for nuclear injection and nuclear envelope integrity (Vankan et al., 1992). Immediately after injection, all RNAs were found in the nuclear fraction (Fig. 1A, lanes 1-3). Following a 3-h incubation, splicing of the precursor RNA was complete and about $54 \%$ of the resulting intron lariat bearing the CTE was found in the cytoplasmic fraction (Fig. 1A, lanes 4-6). As reported previously (Braun et al., 1999), in oocytes coinjected with TAP fragments $61-610$ or $61-372$, export of the intron lariat was directly stimulated and about $95 \%$ reached the cytoplasm (Fig. 1A, lanes 7-12). Recently, Bear et al. (1999) reported the presence of a nuclear export signal between TAP residues 83 and 110. To investigate whether export of the intron lariat was driven by this NES, residues located between positions 88 and 117 were deleted in the context of TAP fragment 61372. Deletion of the putative NES neither affected CTE binding in vitro (data not shown) nor impaired the ability of fragment 61-372 to stimulate CTE-dependent export of the intron lariat (Fig. 1A, lanes 13-16). Thus, residues important for TAP-mediated export of the intron lariat are located within the CTE-binding domain of the protein, but do not overlap with the putative NES.

To investigate CTE-dependent export of U6 RNA, the SRV-1 CTE was fused to the $3^{\prime}$ end of U6 snRNA (U6-CTE). Xenopus oocyte nuclei were injected with a mixture of labeled RNAs consisting of the U6-CTE, $\mathrm{U} 1 \Delta \mathrm{Sm}, \mathrm{U} 5 \Delta \mathrm{Sm}$, and U6 $\Delta \mathrm{ss}$ RNAs and the human

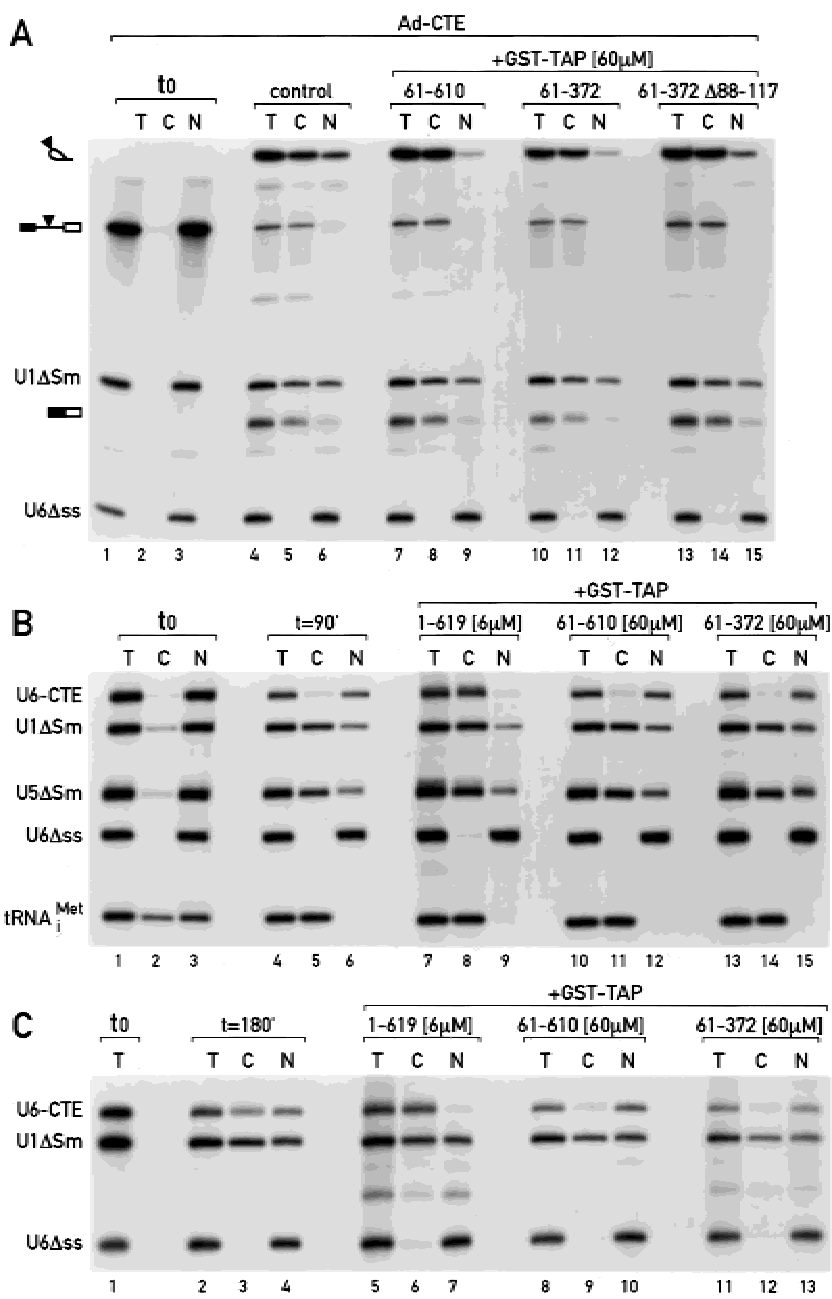

FIGURE 1. The C-terminal domain of TAP promotes export of specific RNA substrates. A: Purified recombinant proteins indicated above the lanes were injected into Xenopus oocyte nuclei together with a mixture of radiolabeled RNAs. This mixture consisted of U1 $\Delta \mathrm{Sm}$ RNA, U6 $\Delta$ ss RNA, and a precursor RNA containing the SRV-1 CTE (Ad-CTE) inserted in the intron. RNA samples from total oocytes (lanes T), cytoplasmic (lanes $\mathrm{C}$ ) and nuclear (lanes N) fractions were collected $3 \mathrm{~h}$ after injection, or immediately after injection ( $\mathrm{t}_{0}$ : lanes $\left.1-3\right)$ and analyzed on $10 \%$ acrylamide/7 M urea denaturing gels. The mature products and intermediates of the splicing reaction are indicated diagrammatically on the left of the panels. The filled triangle represents the CTE. B: Purified recombinant proteins indicated above the lanes were injected into Xenopus oocyte nuclei together with a mixture of radiolabeled RNAs. This mixture consisted of U6-CTE RNA, U1 $\Delta$ Sm, U5 $\Delta$ Sm, and U6 $\Delta$ ss RNAs and human initiator methionyl tRNA. RNA samples from total oocytes (lanes T), cytoplasmic (lanes C) and nuclear (lanes N) fractions were collected 90 min after injection (lanes 4-15) or immediately after injection ( $t_{0}$, lanes $1-3$ ), and analyzed on $8 \%$ acrylamide/7 M urea denaturing gels. C: Purified recombinant proteins indicated above the lanes were injected into the oocyte nuclei together with a mixture of radiolabeled RNAs. This mixture consisted of U6-CTE RNA, U1DSm, and U6 $\Delta$ ss RNAs. RNA samples from total oocytes $(\mathrm{T})$, cytoplasmic $(\mathrm{C})$ and nuclear $(\mathrm{N})$ fractions were collected 180 min after injection (lanes 2-13) or immediately after injection ( $\mathrm{t}_{0}$, lane 1$)$, and analyzed as described in $\mathbf{B}$. In all panels, one oocyte equivalent of RNA, from a pool of 10 oocytes, was loaded per lane. The concentration of the GST-TAP proteins in the injected samples is indicated above the lanes. 
initiator methionyl tRNA. Purified recombinant full-length TAP (1-619), fragment 61-610, and the CTE-binding domain (residues 61-372) were tested for their ability to stimulate export of U6-CTE RNA. After $90 \mathrm{~min}$ of incubation, in control oocytes less than $10 \%$ of U6CTE RNA was exported, whereas about $70 \%$ of U1 and U5 snRNAs reached the cytoplasm and export of tRNA was complete (Fig. 1B, lanes 4-6). Injection of full-length TAP resulted in a strong stimulation of U6CTE RNA export and about $95 \%$ of the injected RNA moved to the cytoplasm (Fig. 1B, lanes 7-9). Export of $U$ snRNAs and of tRNA was not affected (Fig. 1B, lanes 7-9 vs. 4-6). In contrast with the results obtained with the intron-lariat substrate (Fig. 1A), fragment $61-610$ and the CTE-binding domain (61-372) failed to stimulate export of U6-CTE RNA (Fig. 1B, lanes 10-15). Similarly, TAP fragments $1-610$ (see below) and 1-372 (data not shown) failed to stimulate U6-CTE RNA export. Thus, TAP C-terminal residues are required for this function.

To test whether TAP C-terminal truncations have a dominant negative effect over the endogenous TAP, export was allowed to take place for $180 \mathrm{~min}$. In control oocytes, $42 \%$ of the U6-CTE RNA was exported due to the activity of the endogenous protein (Fig. 1C, lanes 2-4). This export could be stimulated by coinjection of full-length TAP (Fig. 1C, lanes 5-7) and strongly inhibited by fragments $61-610$ or $61-372$ (Fig. 1C, lanes 8-13). Export of DHFR mRNA was not stimulated by full-length TAP and was only partially inhibited by TAP fragments at the concentration tested (data not shown). In summary, the C-terminal domain of TAP is required to promote CTE-dependent export of U6 RNA but not of an excised intron lariat. A role of this domain in cellular mRNA export is suggested by the partial inhibitory effect of TAP C-terminal truncations on the export of DHFR mRNA (data not shown). However the observations that TAP is not the limiting factor for $m R N A$ export and that TAP C-terminal truncations only partially inhibit this process indicate that the mode of interaction of TAP with cellular mRNAs is distinct from that with the CTE RNA (see Discussion). Our findings suggest that both the CTE-binding domain and the C-terminal domain of TAP are able to promote export of specific CTE-bearing RNA substrates, most likely by interacting with other components of the nuclear transport machinery. The functionality of these domains appears to be influenced by the nuclear mechanism that retains the CTE-bearing RNP-export substrate within the nucleus or alternatively, by the specific set of RNPassociated proteins.

\section{Selection of Nup98 and three NPC-subcomplexes on immobilized TAP}

To promote export, TAP must interact with other components of the nuclear transport machinery. Under- standing the mechanism of TAP action during the export process requires the dissection, at the molecular level, of these interactions. As a first step towards this end, we fractionated HeLa cell nuclear extracts by affinity chromatography and have identified putative TAP partners. Recombinant TAP was expressed in Escherichia coli as a fusion with two immunoglobulin-binding domains of Protein A from Staphylococcus aureus at its $\mathrm{N}$-terminus and an hexa-histidine tag at its $\mathrm{C}$-terminus (zzTAP-6xHis). The recombinant protein was first purified on a Ni-NTA agarose column and then immobilized on IgG-Sepharose beads. Binding of HeLa cell proteins to immobilized TAP was performed in the absence or in the presence of a mutant form of Ran that has a substitution of glutamine 69 for leucine (RanQ69L) (Klebe et al., 1995). This mutant is GTPase deficient. When loaded with GTP, RanQ69L binds to $\beta$-like transport receptors and modulates the interaction with their substrates (see Introduction). Affinity selections were performed at low salt $(100 \mathrm{mM} \mathrm{KCl})$ or at higher stringency in the presence of $1 \mathrm{M} \mathrm{KCl}$ (high salt). Comparison of the pattern of proteins selected on TAP-coated beads versus control beads by SDS-PAGE revealed the presence of several proteins in the TAP eluates (Fig. 2A, lanes 3-6) that were absent from the control eluates (Fig. 2A, lanes 2 and 7). Inspection of the pattern of proteins selected in the absence or in the presence of RanQ69L indicated that only one protein exhibited a Ran-regulated mode of interaction (Fig. 2A, lanes 3 and 5 vs. 4 and 6 ). This protein was subsequently identified as CRM1 (Table 1). Proteins selected at high salt that were also present in the low-salt eluates were predicted to be prime candidates as TAP partners (Fig. 2A, lanes 5,6 vs. 3, 4). Therefore, these proteins were excised from the gel, digested in gel with trypsin, and the subsequent tryptic peptides were identified by mass spectrometry. The peptides sequenced unambiguously identify RanBP2/Nup358, CAN/Nup214, Nup88/Nup84, RanGAP1, and hGle2/RAE1 as the proteins migrating with apparent molecular weights of $350 \mathrm{kDa}, 250 \mathrm{kDa}$, $89 \mathrm{kDa}, 85 \mathrm{kDa}$, and $43 \mathrm{kDa}$ (Fig. 2A, lanes 5 and 6 and Table 1). Note that the apparent molecular weight of the selected RanGAP1 corresponds to that of its SUMOconjugated form (Matunis et al., 1996; Mahajan et al., 1997; Saitoh et al., 1997). Strikingly, aside from CRM1 and hGle2, the proteins selected at high salt have all been localized to the cytoplasmic fibrils of the NPC (Fig. 2B).

Prompted by these observations we next identified proteins that, although present in substoichiometric amounts, were nevertheless reproducible selected under low salt conditions. The identity of these proteins is indicated on the side of the gel (Fig. 2A, lanes 3 and 4 and Table 1). Three of the proteins selected at low salt were identified as nucleoporins. These were p205 (KIAA0225), Nup93 (Grandi et al., 1997), and Nup98 (Radu et al., 1995). Although p205 has not been defin- 


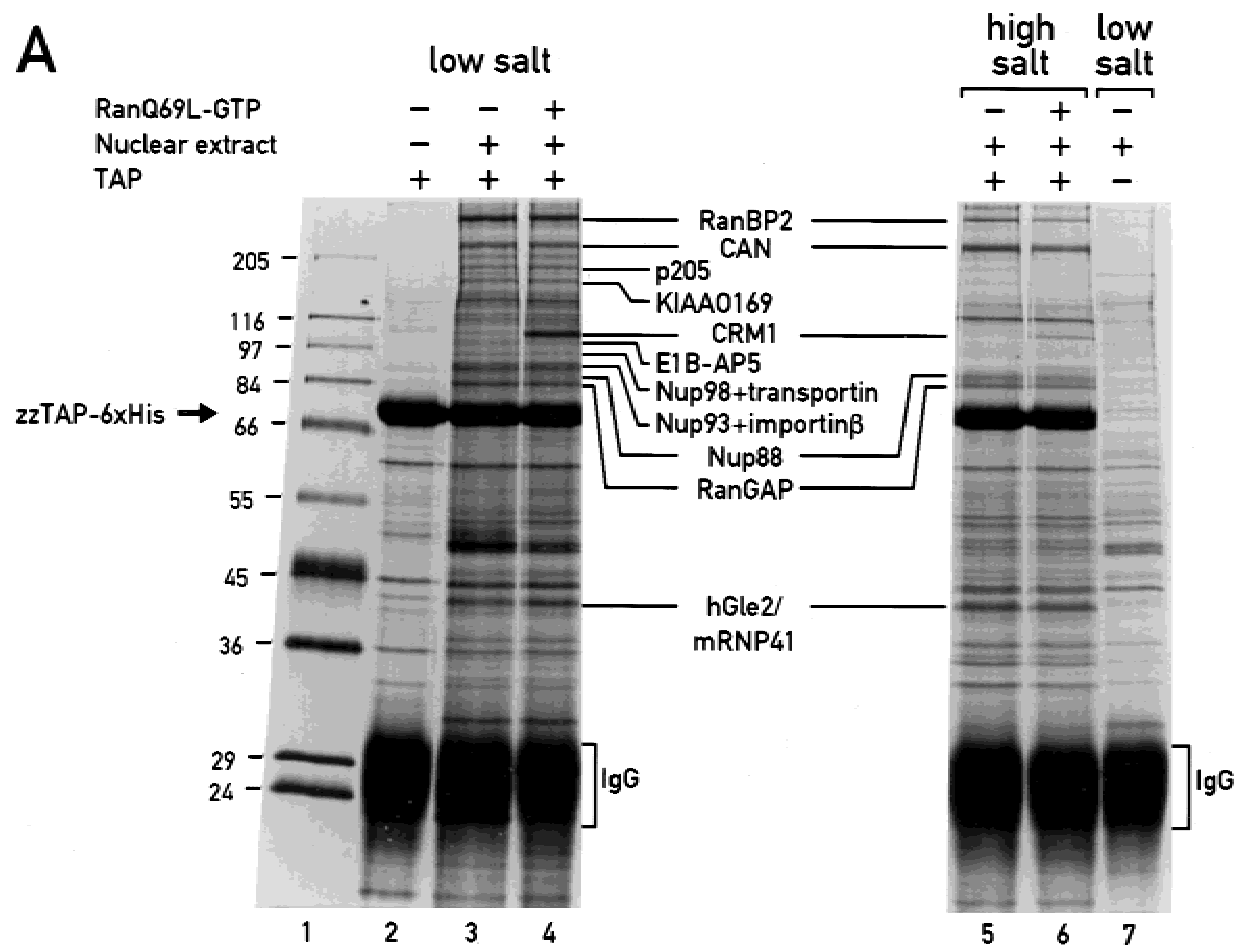

B Proteins selected on immobilised TAP

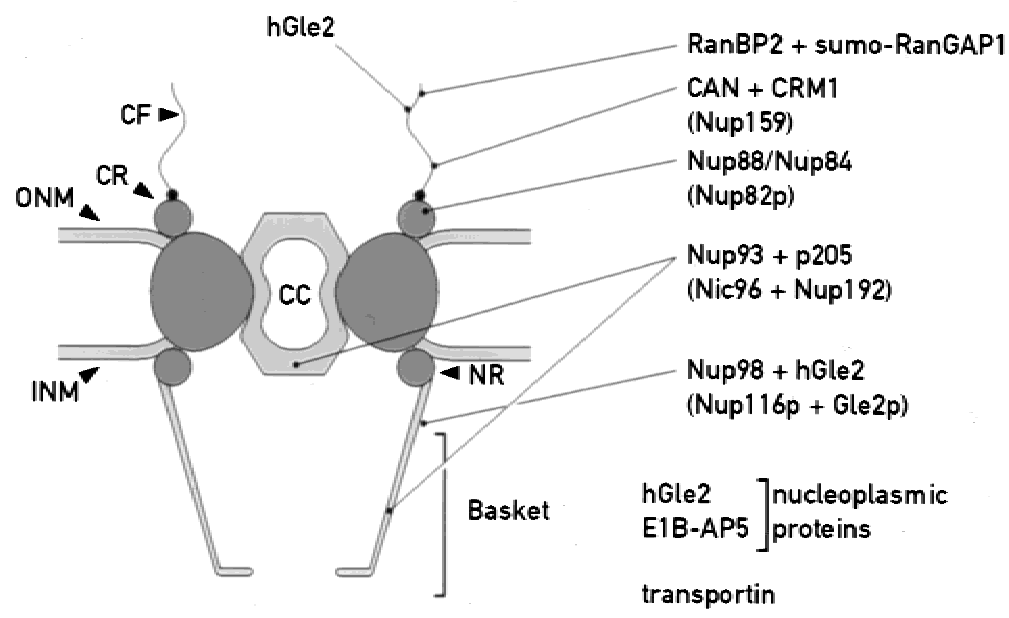

FIGURE 2. Identification of TAP partners. A: HeLa cell nuclear extracts were incubated with IgG-Sepharose beads coated with zzTAP6xHis. Binding reactions were performed in low salt (lanes 2-4 and 7) or in high salt (lanes 5 and 6) and either in the presence or absence of RanQ69L-GTP as indicated above the lanes. After incubation and extensive washing, bound proteins were eluted and analyzed by SDS-PAGE followed by silver staining. Lane 2 shows proteins eluted from the zzTAP-6xHis coated beads when nuclear extracts were omitted. Lane 7 shows proteins eluted from the lgG-Sepahrose beads when TAP was omitted. The identities of the selected proteins are indicated on the side of the gels. B: Proteins selected on the TAP affinity column are shown on this schematical representation of the three-dimensional structure of the nuclear pore complex. The putative yeast homologs are indicated between brackets. Note that with the exception of RanBP2 and RanGAP1, which have been localized to the tip of cytoplasmic filaments, the precise location of other nucleoporins is not well defined. hGle2, like TAP, has been localized in the cytoplasm and nucleoplasm and on both sides of the NPC. It is likely that some of the interactions described in this study may represent consecutive transient steps during the export process. CC: central channel; CF: cytoplasmic filaments; CR: cytoplasmic ring; NR: nuclear ring; ONM: outer nuclear membrane; INM: inner nuclear membrane.

itively proven to be a nucleoporin, it forms a stable complex with Nup93 (Grandi et al., 1997). Transportin and importin- $\beta$ were also identified as proteins comigrating with Nup98 and Nup93, respectively (Table 1).
Finally, a band migrating at approximately $160 \mathrm{kDa}$ was identified as KIAA0169, a protein of unknown function, whereas a protein exhibiting an apparent molecular weight of $98 \mathrm{kDa}$ was identified as E1B-AP5 (Gabler 
Downloaded from rnajournal.cshlp.org on February 18, 2014 - Published by Cold Spring Harbor Laboratory Press

TAP is targeted to the NPC via its $C$-terminal domain

TABLE 1. Identification of TAP partners.

\begin{tabular}{|c|c|c|c|}
\hline $\begin{array}{l}\text { Approximate } \\
\text { molecular } \\
\text { weight }\end{array}$ & Protein name & Method of identification & $\begin{array}{l}\text { Accession } \\
\text { number }\end{array}$ \\
\hline 350 & RanBP2/Nup358 & Maldi (sequence coverage: $26 \%$ ) and western blot & P49792 \\
\hline 250 & CAN/Nup214 & Maldi (sequence coverage: $14 \%$ ) & P35658 \\
\hline 180 & p205/KIAA0225 & $\begin{array}{l}\text { QCLGLLSR, DLPSADSVQYR, IQQGALELLR, AQIEQVIANCEHK, } \\
\text { LVGDFTHDQSISQK }\end{array}$ & D86978 \\
\hline 160 & KIAA0169 & LITTLVK, LAIQLLK, LLYPLGGQTNLR, LLEGLSYYKPPSPSSAEK & D79991 \\
\hline 110 & CRM1 & Western blot & D89729 \\
\hline 98 & E1B-AP5 & LIQIAAR, EALGGQALYPHVLVK & E1311327 \\
\hline 97 & Nup98+ Transportin & $\begin{array}{l}\text { Western blot } \\
\text { Western blot }\end{array}$ & L39991 \\
\hline 93 & Nup93 & AFDIIER, LVPLNQESVEER, TLITFAGMIPYR & D42085 \\
\hline 93 & Importin- $\beta$ & $\begin{array}{l}\text { TTLVIMER, VAAGLQIK, SSAYESLMEIVK, VAALQNLVK, } \\
\text { LVEARPMIHELLTEGR,LAATNALLNSLEFTK, TLATWATK }\end{array}$ & L38951 \\
\hline 89 & Nup88 & Maldi (sequence coverage: $32 \%$ ) & AA704153 \\
\hline 85 & RanGAP1 & Maldi (sequence coverage: $40 \%$ ) & P46060 \\
\hline 43 & hGle2/hRae1 & $\begin{array}{l}\text { VAIHYINPPNPAK, YEELQITAGR, NYIFLR, GLIVYQLENQPSEFR, } \\
\text { NAAEELKPR and Western blot }\end{array}$ & P78406 \\
\hline 17 & UBC1 & GTPWEGGLFK & P50550 \\
\hline
\end{tabular}

et al., 1998). E1B-AP5, originally identified in a screen for cellular proteins interacting with the adenovirus protein E1B-55, shows extensive homology with hnRNP U and other hnRNP proteins and is likely to directly associate with mRNAs (Gabler et al., 1998). Thus, the search for TAP interacting partners has led to the identification of transportin, importin- $\beta$, two mRNAassociated proteins (hGle2 and E1B-AP5) and several nucleoporins. The functional role of these interactions is analyzed below.

\section{TAP interacts with hGle2 and E1B-AP5, two mRNA-associated proteins implicated in mRNA export}

To determine the specificity of the interaction between TAP and the selected proteins, we performed in vitro binding assays. $\left[{ }^{35} \mathrm{~S}\right]$ methionine-labeled putative TAP partners were synthesized in vitro in rabbit reticulocyte lysates and assayed for binding to glutathione agarose beads coated with either GST-TAP, GST alone, or various TAP fragments fused to GST. Binding of RanBP2, p205, and KIAA0169 was not further investigated. In preliminary experiments we noticed that some of the selected proteins bound to GST-TAP only in the presence of nuclear extracts. This was the case for CRM1, importin- $\beta$, Nup88, Nup93, and RanGAP1 (data not shown). Additional experiments indicate that TAP/CRM1 interaction was bridged by CAN and probably by other nucleoporins present in the column (data not shown). Because TAP-mediated export is distinct from the CRM1 export pathway (Pasquinelli et al., 1997; Saavedra et al., 1997; Zolotukhin \& Felber, 1997; Bogerd et al., 1998; Otero et al., 1998), we conclude that TAP/CRM1 interaction is not relevant for TAP function. However, our results indicate that the two proteins share common binding sites at the NPC (see below).

Binding of in vitro-synthesized transportin, CAN, Nup98, hGle2, and E1B-AP5 to GST-TAP neither required nor was stimulated by addition of nuclear extracts (Figs. 3, 4, and 5 and data not shown) suggesting that these interactions may be direct, and thus were characterized further. When GST pull-down assays were performed with various fragments of TAP, hGle2 interacted with the C-terminal domain of TAP (TAP371619) but not with its N-terminal domain (TAP1-372) (Fig. 3A, lanes 3-5). The C-terminal domain of TAP also interacted with all nucleoporins analyzed in this study (Fig. 7). In contrast, E1B-AP5 associates with the $\mathrm{N}$-terminus (TAP1-372) but not with the C-terminal domain of TAP (TAP371-619; Fig. 3B, lanes 4 and 5). Shorter N-terminal TAP fragments (TAP1-265 and TAP1-185) exhibited a reduced binding affinity for E1BAP5 (Fig. 3B, lanes 6 and 7), whereas deletion of TAP's first 60 amino acids severely impaired its binding to E1B-AP5 (TAP61-372; Fig. 3B, lane 8). This observation was supported further by the GST pull-down assay shown in Figure 3C. In this assay, various TAP deletion mutants synthesized in vitro were tested for their ability to bind to an E1B-AP5 fragment expressed in E. coli as a GST fusion. This E1B-AP5 fragment (101-619) binds TAP with the same efficiency as the full-length protein (data not shown). Deletion of TAP residues 22-55 severely impaired its binding to E1B-AP5 (Fig. 3C, lanes 4-6), whereas short deletions downstream of position 55 had no effect. Together, our results indicate that fragment 1-372 represents the E1B-AP5 binding domain of TAP. Within this domain, the first 55 amino acids appear to contribute substantially to the affinity of the interaction. Although we can- 
A

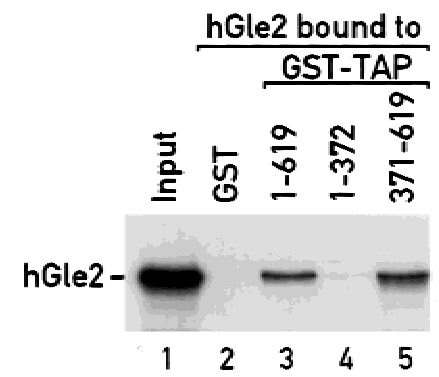

B
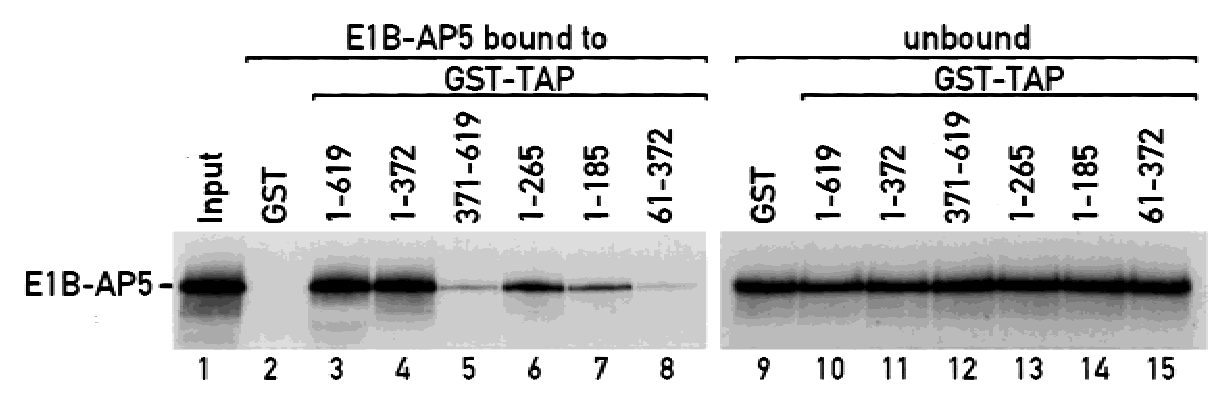

C

$\begin{array}{ccc}\text { TAP } & \text { TAP } & \text { TAP } \\ 1-619 & \Delta 22-55 & \Delta 53-71\end{array}$

TAP

TAP

TAP

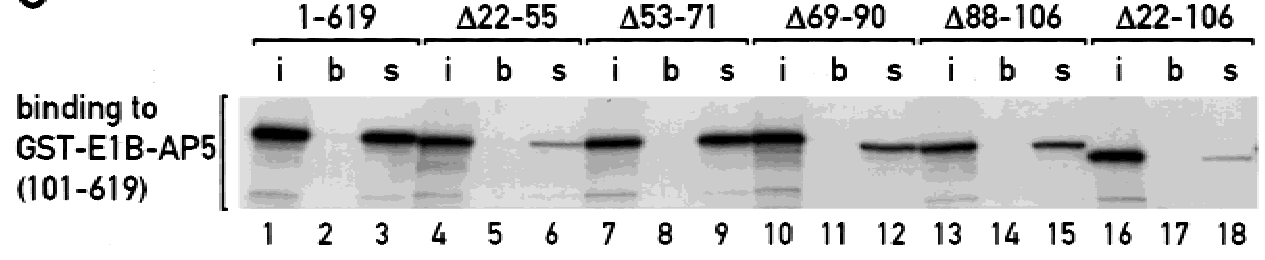

D

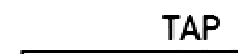

TAP295

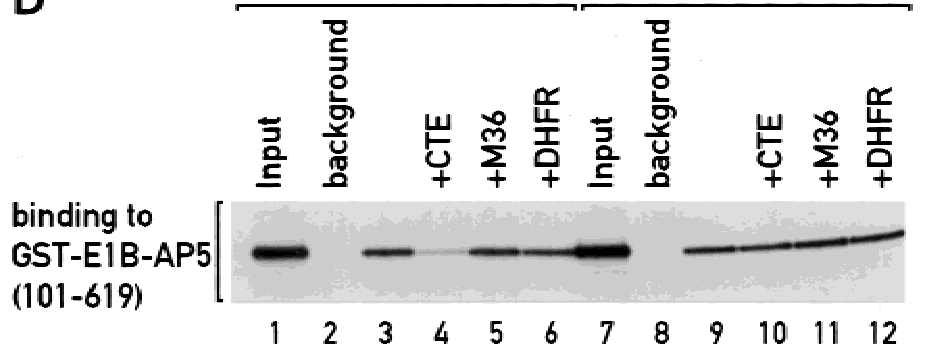

FIGURE 3. TAP interacts with hGle2 and E1B-AP5. $\left[{ }^{35}\right.$ S]methionine-labeled hGle2 (A) or E1B-AP5 (B) was synthesized in vitro in rabbit reticulocyte lysates. Five-microliter samples from the lysates were incubated with glutathione agarose beads precoated with GST (lanes 2), GST-TAP (lanes 3) or several TAP truncations as indicated. C: GST pull-down assays were performed with [ ${ }^{35} \mathrm{~S}$ ] methionine-labeled TAP and various TAP mutants and recombinant GST-E1B-AP5 (fragment 101619). Lanes b show the background obtained with glutathione agarose beads when GST-E1B-AP5 was omitted and lanes s show the proteins selected on immobilized GST-E1B-AP5. D: GST pull-down assays were performed with [ ${ }^{35}$ S] methioninelabeled TAP or TAP mutant 295 and recombinant GST-E1B-AP5. CTE, M36, and DHFR RNAs were added to the binding reactions as indicated. The concentration of the RNAs was $0.4 \mu \mathrm{M}$. In all panels, one tenth of the inputs (lanes i), one twentieth of the supernatants and one third of the bound fractions were analyzed on SDS-PAGE followed by fluorography.

not rule out that the interaction of TAP with hGle2 and E1B-AP5 is mediated by RNA or by a factor present in the reticulocyte lysate, we consider this possibility unlikely as these interactions were neither prevented by microccocal nuclease treatment nor stimulated by including increasing amounts of HeLa extracts, reticulocyte lysate, or RNA in the binding reactions (data not shown and Fig. 3D).

Because the E1B-AP5-binding domain of TAP overlaps with its CTE-binding domain, we next tested the effect of the CTE RNA on TAP/E1B-AP5 interaction. Full-length TAP and an alanine scan mutant (TAP295) that no longer interacts with the CTE RNA (Braun et al., 1999) were selected on immobilized E1B-AP5 in the presence of the CTE RNA. Figure 3D shows that the CTE RNA prevented TAP binding to E1B-AP5 (lane 4 vs. lane 3) whereas it had no effect on TAP295 binding (lanes 9 and 10). Thus, the inhibitory effect of the CTE RNA on TAP/E1B-AP5 interaction was mediated by its direct binding to TAP. The specificity of this inhibition 


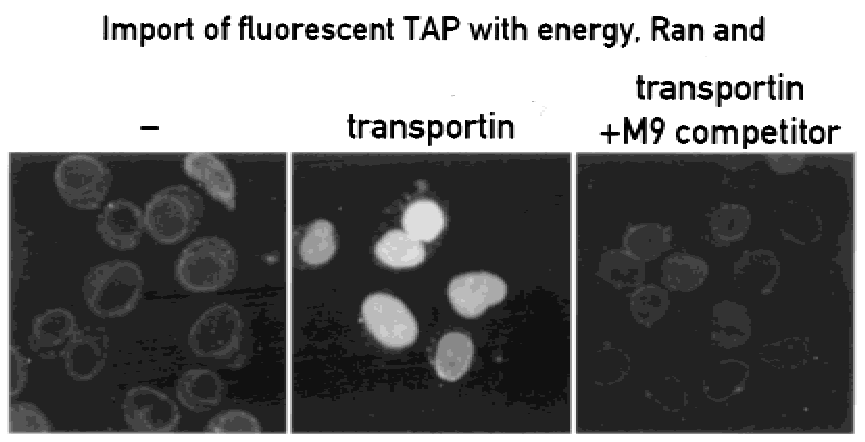

B Binding of transportin to immobilised Tap from an E.coli lysate

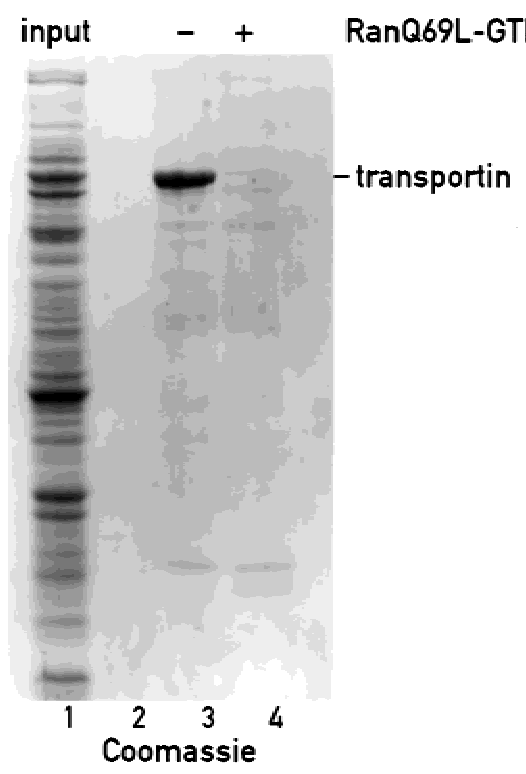

C

Binding of TAP to immobilised transportin

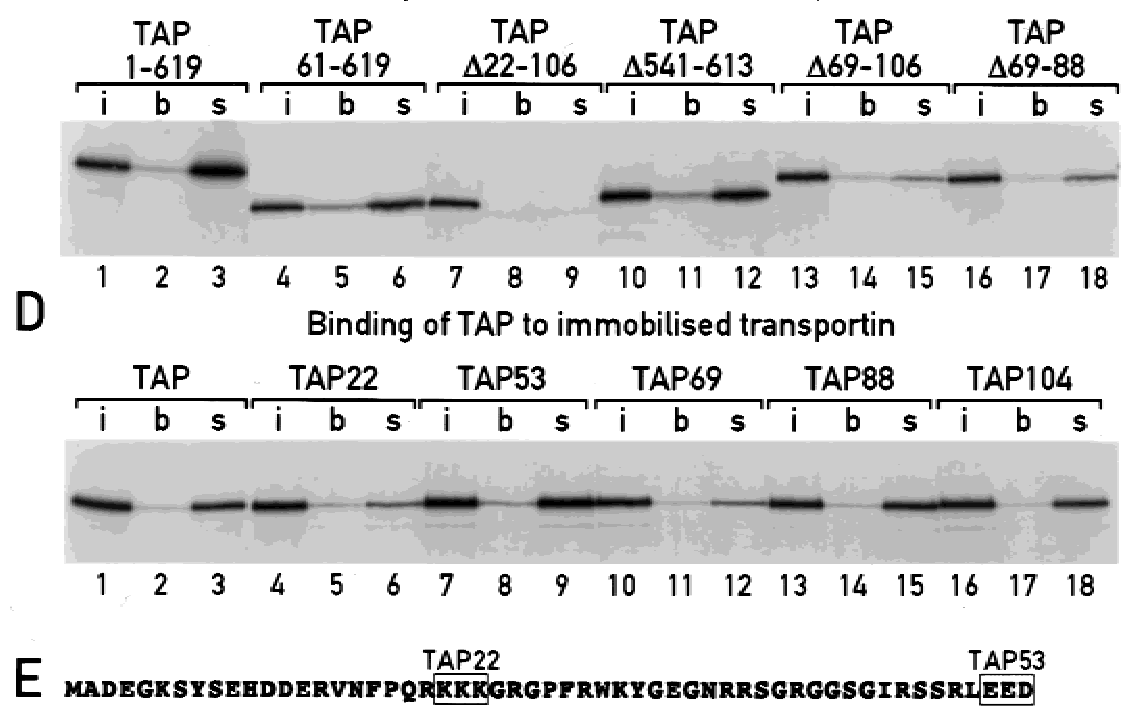

61

FIGURE 4. Nuclear import of TAP requires interaction with transportin. A: 2.5-3 $\mu \mathrm{M}$ of fluorescent TAP were incubated with permeabilized HeLa cells in the presence of an energy regenerating system, a Ran mix and, where indicated, $1.75 \mu \mathrm{M}$ of transportin was added. Without transportin (-), TAP was detected predominantly at the nuclear envelope. Addition of transportin resulted in strong nuclear accumulation of TAP. No import was detectable when import reactions were supplemented with the hnRNP A1 M9 domain (transportin + M9 competitor). The localization of fluorescent TAP was documented after $10 \mathrm{~min}$ of import reaction by live confocal fluorescence microscopy. B: A lysate from E. coli expressing transportin was incubated with IgG-Sepharose beads precoated with zzTAP-6xHis. Binding of transportin to zzTAP was tested in the presence $(+)$ or absence $(-)$ of RanQ69L-GTP. One tenth of the input (lane 1) and one quarter of the bound fractions (lanes 3 and 4) were analyzed on SDS-PAGE followed by Coomassie staining. The position of transportin is indicated on the right of the gel. C,D: Pull-down assays were performed with $\left.{ }^{35} \mathrm{~S}\right]$ methionine-labeled TAP or various TAP mutants and immobilized zz-transportin on IgG-Sepharose beads. One tenth of the input (lanes i) and one quarter of the bound fractions (lanes s) were analyzed on SDS-PAGE followed by fluorography. Lanes b show the background obtained with IgGSepharose beads when zz-transportin was omitted. E: Positions of the alanine scan mutants are shown on the primary amino acid sequence of human TAP. The black dot indicates the position of residue 61 . Residues necessary and sufficient for transportin binding are located between positions 61-102.

was confirmed by the observation that similar molar amounts of either DHFR mRNA or of a mutant CTE RNA (mutant M36) that does not interact with TAP (Grüter et al., 1998) had no inhibitory effect (Fig. 3D, lanes 5 and 6 and 11 and 12).

In summary, our results indicate that while the C-terminal domain of TAP interacts with hGle2 and with several nucleoporins (see below), its $\mathrm{N}$-terminal do- main its likely to mediate substrate binding as it contains the CTE-binding domain (Braun et al., 1999; Kang \& Cullen, 1999) and interacts with at least one hnRNPlike protein, E1B-AP5 (Gabler et al., 1998), that may recruit TAP to the mRNP complexes. Although the role of E1B-AP5 in the export of cellular mRNAs needs further investigation, we conclude that E1B-AP5 is unlikely to be involved in the export of CTE-bearing RNAs, 


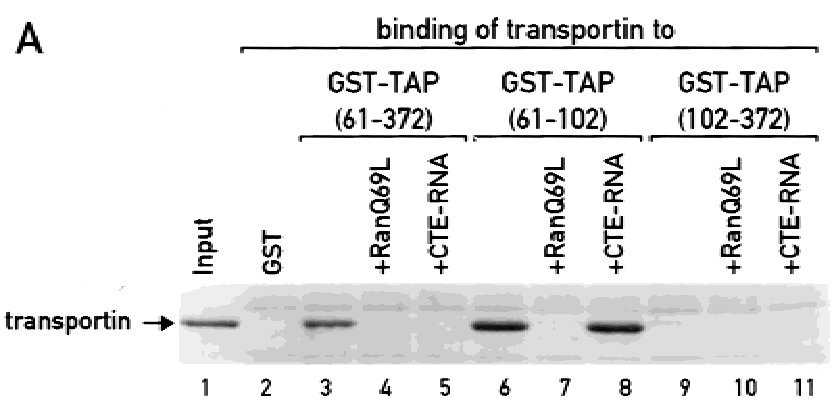

B Import assay in Xenopus oocytes

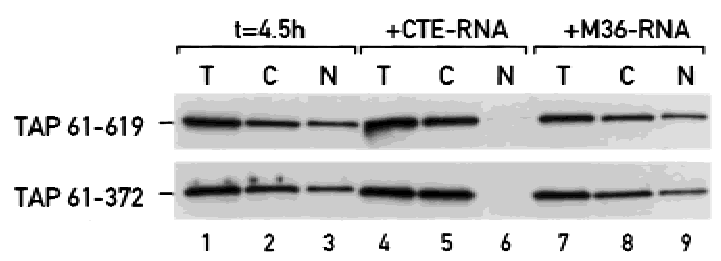

C Import of fluorescent TAP with energy. Ran, transportin and

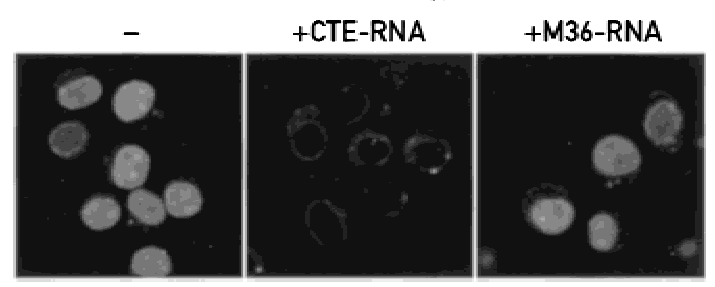

FIGURE 5. Binding of TAP to the CTE RNA prevents its interaction with transportin. A: A lysate from $E$. coli expressing transportin was incubated with glutathione agarose beads precoated with recombinant TAP fragments 61-372, 61-102, and 102-372 fused to GST. When indicated, RanQ69L-GTP (lanes 4,7 , and 10) or CTE RNA (lanes 5, 8, and 11) were added to the binding reactions. One tenth of the input (lane 1) and one quarter of the bound fractions (lanes 311) were analyzed on SDS-PAGE followed by Coomassie staining. The concentration of the CTE RNA in the binding reactions was $0.2 \mathrm{mg} / \mathrm{mL}$. B: $\left[{ }^{35} \mathrm{~S}\right]$ methionine-labeled TAP fragments $61-619$ and 61-372 were injected into Xenopus oocyte cytoplasm along with CTE or M36 RNAs as indicated. Protein samples from total oocytes (lanes T), cytoplasmic (lanes C) and nuclear (lanes N) fractions were collected $4.5 \mathrm{~h}$ after injection and analyzed on SDS-PAGE followed by fluorography. The concentration of the RNAs in the injected samples was $2.5 \mathrm{mg} / \mathrm{mL}$. C: Nuclear import of fluorescent TAP was visualized in permeabilized HeLa cells as described in Figure 4A. When TAP was preincubated with $2.7 \mu \mathrm{M}$ of CTE RNA, no import was detectable. As a control, TAP was preincubated with $2.7 \mu \mathrm{M}$ of M36 RNA, which had no significant effect on its import.

as binding of TAP to the CTE RNA prevents its interaction with E1B-AP5, indicating that their binding by TAP are mutually exclusive.

\section{TAP import is mainly driven by transportin}

TAP import is driven by an N-terminal NLS located within amino acids 69-104 (Bear et al., 1999; Kang \& Cullen, 1999; Katahira et al., 1999). The presence of transportin in our affinity column prompted us to investigate whether TAP import was mediated by trans- portin. TAP nuclear import was analyzed in vitro in permeabilized HeLa cells. In the absence of transportin, TAP bound to the nuclear envelope of the permeabilized cells (Fig. 4A). Addition of recombinant transportin promoted the accumulation of TAP within the nucleoplasm. This nuclear uptake was competed by excess of the M9 domain of hnRNP A1 (Siomi \& Dreyfuss, 1995), which acts as a competitive inhibitor of transportin-mediated nuclear import (Pollard et al., 1996; Siomi et al., 1997).

The binding of transportin to TAP was confirmed using recombinant proteins. Transportin bound specifically and directly to immobilized TAP from a total E. coli lysate (Fig. 4B, lane 3); this binding was prevented by RanQ69L-GTP (Fig. 4B, lane 4). To identify the sequences of TAP recognized by transportin, we performed in vitro binding assays. ${ }^{35}$ S]methioninelabeled TAP and various deletion mutants were synthesized in vitro in rabbit reticulocyte lysates. The labeled proteins were then tested for binding to recombinant Protein A-tagged transportin immobilized on IgG-sepharose beads. As shown in Figure 4C, an internal deletion that removed residues located within positions 22-106 abolished the interaction with transportin (lanes 7-9), whereas deletion of the C-terminal domain of TAP (TAP $\Delta 541-613$ ) did not affect this interaction (lanes 10-12). Further analysis indicated that deletion of the first 60 amino acids of TAP (TAP61619) did not affect transportin binding (Fig. 4C, lanes 4-6), whereas deletion of residues 69-106 or residues 69-88 (Fig. 4C, lanes 13-18) impaired binding. Thus, residues important for transportin binding are located within positions 69-106, while residues located within fragment 1-60 may contribute to, but are not absolutely required for, the interaction. These results are consistent with the observation that residues 1-60 do not contribute to TAP nuclear uptake in HeLa cells (Bear et al., 1999; Kang \& Cullen, 1999).

Alanine substitutions of residues located around position 69 have been shown to impair NLS activity in vivo (Bear et al., 1999; Kang \& Cullen, 1999). To identify residues important for transportin binding, we tested a collection of TAP alanine scan mutants (Braun et al., 1999; see Fig. 4E) for their ability to bind to immobilized transportin. Substitution of residues 22-24 (TAP22) or residues 69-71 (TAP69) by alanines substantially reduced transportin binding (Fig. 4D, lanes 4-6 and 10-12). Alanine scan mutants TAP53, TAP88, and TAP104 had no effect (Fig. 4D, lanes 7-9 and 13-18). Because the alanine scan mutant TAP22 had a more severe effect than the deletion of residues 1-60 (TAP61-619), we concluded that residues 22-24 may not directly contact transportin, but their substitution by alanines may affect the overall conformation of the $\mathrm{N}$-terminal domain. Thus, the first hundred $\mathrm{N}$-terminal residues of TAP provide a binding site for transportin. Within this domain residues 69-106 are necessary and 
sufficient (see below; Fig. 5A) for the interaction. Thus, the transportin-binding site overlaps with the previously identified TAP NLS (Bear et al., 1999; Kang \& Cullen, 1999; Katahira et al., 1999). Furthermore, mutations that affect NLS activity in vivo also reduce transportin binding in vitro. Therefore we conclude that transportin promotes TAP import by directly binding to its N-terminal NLS. Note that although importin- $\beta$ interacts with TAP in vitro (Table 1 and data not shown) it is unlikely to substantially contribute to its import in vivo as mutations that impair TAP nuclear uptake do not affect its binding in vitro (data not shown).

The transportin-binding site being located within the CTE-binding domain, we then tested whether transportin binding to TAP could dissociate preformed TAP/ CTE RNA complexes. This could provide a mechanism for the release of the CTE RNA in the cytoplasm and the recycling of TAP back to the nucleus after one round of export. Unexpectedly, binding of TAP to the CTE RNA prevented its interaction with transportin as shown in Figure 5A. In this assay transportin was selected from a total $E$. coli lysate on immobilized recombinant TAP fragments. The specificity of the interaction was tested by adding RanQ69L-GTP (Fig. 5A, lanes 4, 7, and 10). The CTE RNA prevented the interaction of transportin with TAP fragment 61-372, whereas it had no effect on TAP fragments to which it could not bind (Fig. 5A, lanes 6-8). Thus, the inhibitory effect of the CTE RNA is exerted through its direct binding to TAP. If the CTE RNA prevents TAP binding by transportin, then it should inhibit TAP nuclear uptake. This hypothesis was tested both in vivo, in Xenopus oocytes, and in vitro in permeabilized HeLa cells. In both systems the presence of the CTE RNA strongly inhibited TAP nuclear import (Fig. 5B,C), whereas the M36 RNA had no effect. Thus, binding of TAP to the CTE RNA precludes its interaction with transportin, and inhibits the import driven by the N-terminal NLS. As a consequence, TAP molecules exporting the CTE RNA may not be imported back to the nucleus, providing a rational for the strong inhibitory effect of the CTE RNA on the export of cellular mRNAs (Pasquinelli et al., 1997; Saavedra et al., 1997).

\section{TAP directly interacts with the FG-repeat domains of Nup98 and CAN}

A direct interaction between TAP and the C-terminal domain of CAN was reported by Katahira et al. (1999). In this study we analyzed the interaction between TAP and the nucleoporin Nup98 and further characterized its interaction with CAN. Previously, the C-terminal domain of CAN (residues 1690-2090), containing the FGrepeats, was shown to interact with CRM1 (Fornerod et al., 1997b). Figure 6A shows a comparison of TAP and CRM1 binding to $\mathrm{C}$-terminal fragments of CAN. In this assay, CAN fragments were expressed in E. coli as
GST fusions and immobilized on glutathione agarose beads, and TAP and CRM1 were translated in vitro. Both TAP and CRM1 bound to a fragment of CAN encompassing residues 1690-2090 (Fig. 6A, lanes 4 and 10 ) and to a shorter fragment encompassing residues 1690-1894 (Fig. 6A, lanes 3 and 8). A fragment of CAN comprising residues 1983-2090 no longer interacted with TAP (data not shown). Furthermore, TAP binding was not regulated by Ran, whereas binding of CRM1 was dramatically stimulated by RanQ69L-GTP (Fig. 6A, lanes 8 and 10 vs. 7 and 9), as previously reported (Askjaer et al., 1999; Kehlenbach et al., 1999). Similarly, TAP/Nup98 interaction was mediated by the $\mathrm{N}$-terminal FG-repeat-containing domain of the nucleoporin (residues 66-515; data not shown). This domain also interacts with CRM1, but its binding is not dramatically stimulated by RanQ69L-GTP (data not shown).

To confirm that the interaction between Nup98 and TAP was direct, we immobilized bacterially expressed GST-Nup98(66-515) or GST alone on glutathione agarose beads. Beads were then incubated with total lysates from $E$. coli expressing zzTAP-6xHis. Figure 6B shows that stoichiometric amounts of TAP could be selected from $E$. coli lysates on immobilized GSTNup98 (lane 6), but not on GST (lane 4). Similar results were obtained with immobilized GST-CAN (data not shown). These results indicate that the interaction between TAP and Nup98 or CAN is direct and is mediated by the FG-repeat domain of the nucleoporins.

\section{The C-terminal domain of TAP interacts with multiple nucleoporins and defines its NPC-binding domain}

To determine the functional role of CAN and Nup98 binding by TAP, we defined more precisely the domains of TAP involved in these interactions. Pull-down assays were performed with various TAP fragments fused to GST and in vitro translated CAN (1690-1894) or Nup98. CAN and Nup98 bound to the full-length TAP and to its C-terminal domain (TAP371-619) but not to the $\mathrm{N}$-terminal domain (TAP1-372; Fig. 7A, lanes 3-5). Both nucleoporins also bound to TAP fragments 470619 (Fig. 7A, lane 7) and 508-619 (Fig. 7B, lane 5), whereas their binding to fragments $371-551$ and 540 619 was impaired (Fig. 7A, lanes 6 and 8). These results indicate that residues important for CAN and Nup98 binding are located at the very $\mathrm{C}$-terminal end of TAP within residues 508 and 619. As the FG-repeat domains of CAN and Nup98 mediate their interaction with the C-terminal domain of TAP, we also investigated whether this domain could interact with other FG-repeat-containing nucleoporins. As shown in Figure $7 A, B$, both p62 and the repeat domain of Nup153 interacted with TAP fragments 371-619, 470-619, and 508-619, but had a reduced or no affinity for fragment 

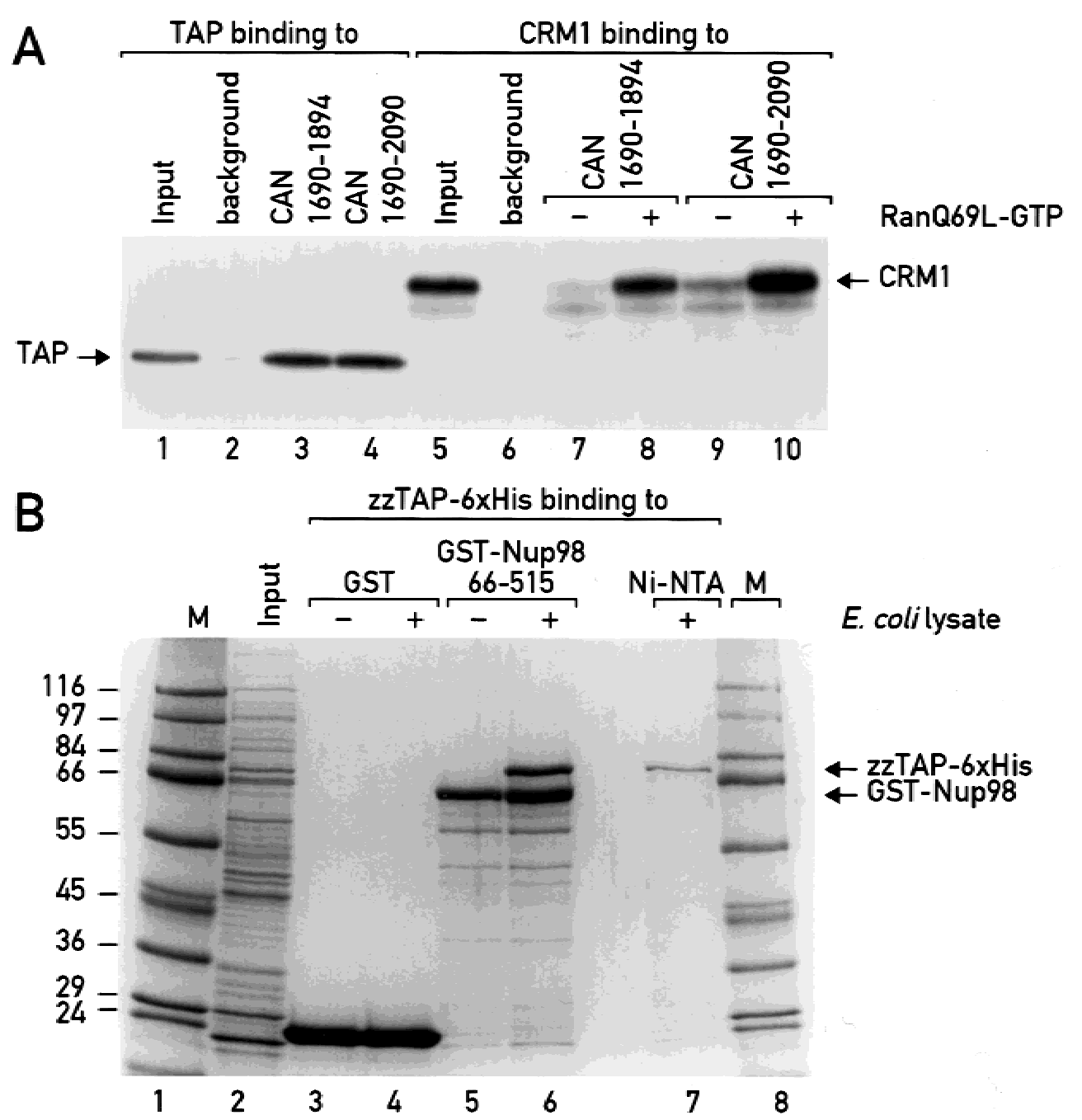

FIGURE 6. TAP directly interacts with the FG-repeat domain of CAN and Nup98. A: GST pull-down assays were performed with $\left[{ }^{35}\right.$ S] methionine-labeled TAP or CRM1 and the recombinant proteins indicated above the lanes. Binding of CRM1 to CAN fragments was tested in the presence $(+)$ or absence $(-)$ of RanQ69L. One tenth of the inputs (lanes 1 and 5) and one quarter of the bound fractions (lanes 2-4 and 6-10) were analyzed on SDS-PAGE followed by fluorography. B: Lysates from E. coli expressing zzTAP-6xHis were incubated with glutathione agarose beads precoated with GST (lane 4), GST-Nup98 (66-515) (lane 6), or with $\mathrm{Ni}^{+2}$-NTA agarose beads (lane 7). Bound proteins were eluted with SDS-sample buffer. One twentieth of the input (lanes 1) and one quarter of the bound fractions (lanes 3-7) were analyzed on SDS-PAGE followed by Coomassie stain. For each GST pull-down assay the background obtained in the absence of lysates is shown (lanes 3 and 5). The positions of zzTAP6xHis and GST-Nup98 are indicated on the right of the gel.

371-551. hCG1, the putative human homolog of yeast Rip1p/Nup42p, appeared to have multiple binding sites on the C-terminal domain of TAP (Fig. 7A, lanes 5-8). Thus, among the TAP truncations tested, fragment 508619 is the smallest fragment that interacts with the different nucleoporins as efficiently as full-length TAP.

Katahira et al. (1999) reported the identification of the putative human Mtr2p functional homolog that they called p15. In yeast cells lacking Mtr2p, p15 expression was required to localize human TAP to the nuclear rim (Katahira et al., 1999). However, the observation that TAP binding to CAN and Nup98 is direct (Fig. 6) suggests that in HeLa cells TAP may not depend on p15 binding to associate with the pores. To investigate whether p15 could mediate the association of TAP with the NPC, we first defined TAP residues involved in this interaction. As shown in Figure 7A, p15 interacted with TAP fragment 371-619. However, unlike most nucleoporins analyzed, p15 interacted with fragment 371551 but not with fragment 470-619 (Fig. 7A, lanes 6 and 7 ). These results indicate that $p 15$ is not mediating the interaction of TAP with the nucleoporins analyzed in this study.

To define more precisely the sequence requirements for the interactions of TAP with nucleoporins and with p15, we also tested the binding of these proteins to several TAP derivatives containing internal deletions within the C-terminal domain. Figure 7B shows that deletion of residues 437 to 507 (TAP $\Delta 437-507$ ) did not affect nucleoporin binding but strongly reduced TAP 
TAP is targeted to the NPC via its C-terminal domain

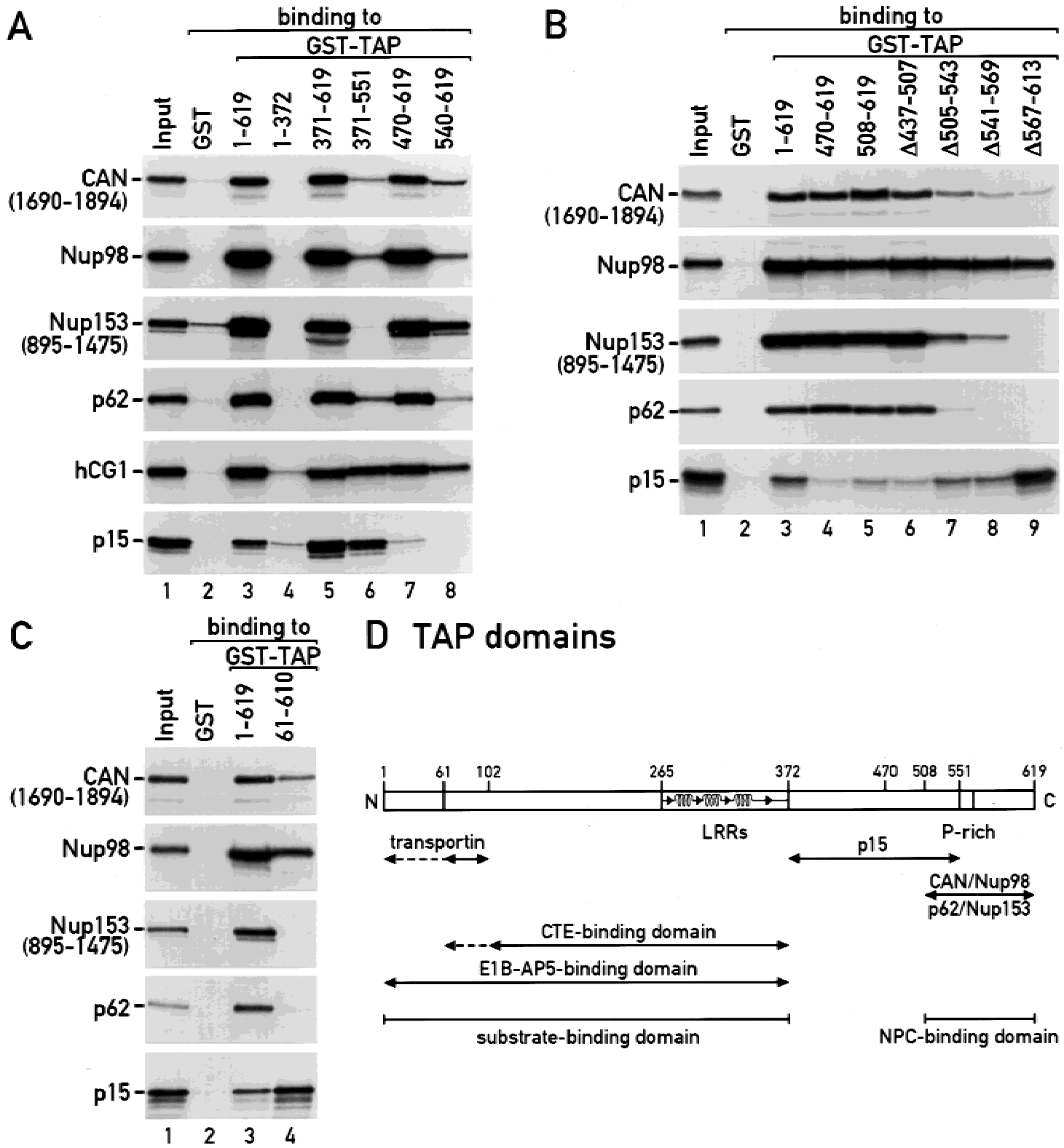

FIGURE 7. The C-terminal domain of TAP interacts with multiple components of the NPC. A,B,C: GST pull-down assays were performed with $\left[{ }^{35} \mathrm{~S}\right.$ ] methionine-labeled p15 or the nucleoporins indicated on the left of the panels and various fragments of TAP fused to GST, as indicated above the lanes. One tenth of the input and one quarter of the bound fractions were analyzed on SDS-PAGE followed by fluorography. D: Domain organization of human TAP protein. TAP domains defined in this and previous studies (Braun et al., 1999) are indicated. The predicted folding within the LRRs is shown diagrammatically. The transportin-binding site defined in this study overlaps with the previously identified TAP NLS.

binding to p15 (lane 6). Interestingly, deletions within positions 505-619 reduced or abolished binding of most nucleoporins tested, with the exception of Nup98. The strongest effect was obtained for the deletion located most C-terminal (TAP $\Delta 567-613$, Fig. 7B, lane 9), indicating that the very $\mathrm{C}$-terminal residues from TAP are important for nucleoporin binding. In contrast, p15 binding was not affected by this C-terminal deletion (Fig. 7B, lane 9). Note that TAP $\Delta 567-613$ exhibits the same binding properties than TAP fragment 61-610 (Fig. 7C). Indeed, these fragments bind $\mathrm{p} 15$ and Nup98, exhibit a reduced affinity for CAN, but do not interact with p62 or Nup153. These results indicate that, although all nucleoporins tested bound TAP fragment 508-619, their modes of interaction are not equivalent.

Our results indicate that residues important for the interaction of TAP with p15 and with nucleoporins are distinct. Thus, the C-terminus of TAP comprises two distinct interaction domains. Residues 371-551 are implicated in $\mathrm{p} 15$ binding whereas residues 508-619 have the ability to interact with several FG-repeat-containing nucleoporins, and therefore represent the NPC-binding 
domain of TAP (Fig. 7D). This conclusion is supported by the experiments described below.

\section{TAP is localized within the nucleoplasm and on both sides of the nuclear pore complex}

The interaction of TAP with nucleoporins suggests that a fraction of the protein may localize to the NPC. By indirect immunofluorescence microscopy, TAP was predominantly localized within the nucleoplasm. However, when cells were extracted with high salt, a fraction of the protein was also detected in a rim at the nuclear periphery (Katahira et al., 1999). In this study we investigate whether the nuclear rim-associated fraction of TAP could be visualized by treating HeLa cells with Triton X-100 prior to fixation, as this procedure has been more commonly used to detect NPC-associated proteins. In unextracted HeLa cells, TAP was evenly detected in the nucleoplasm and was excluded from the nucleolus (Fig. 8A). A fraction of TAP was also detected in the cytoplasm. When HeLa cells were treated with Triton X-100 prior to fixation, the nucleoplasmic and cytoplasmic pools of TAP were solubilized and only the fraction associated with the nuclear envelope was resistant to detergent extraction (Fig. 8B). Furthermore, the nuclear rim-associated fraction of TAP colocalizes with the labeling produced by a monoclonal antibody directed against nucleoporins, confirming that TAP associates with the NPC (Fig. 8C-E). These results validate the use of Triton X-100 extraction to visualize the pool of TAP associated with the NPC.

To clearly determine the location of TAP within the NPC on an ultrastructural level we carried out preembedding immunoelectron microscopy on isolated nuclei from Xenopus oocytes. TAP was expressed in Xenopus oocytes as a fusion with two immunoglobulinbinding domains of Protein A (zzTAP). As documented in Figure 8F,G, we found that a colloidal gold-conjugated antibody to Protein A labeled the cytoplasmic periphery of the NPC. To allow the antibody to reach the nuclear side of the nuclear envelope, isolated nuclei were treated with Triton X-100 before labeling (Fig. 8H,I). In this case, gold particles associated with the pore were found on the cytoplasmic side of the NPC, between 50 and $60 \mathrm{~nm}$ from the central plane of the NPC, but also on the nuclear side of the pore at distances between 50 and $100 \mathrm{~nm}$ from the central plane of the NPC. These positions correspond to the distal part of the cytoplasmic filaments and to the nuclear baskets (Panté et al., 1994). The NPC labeling was specific, as it was not detected in control oocytes (data not shown). Similar results were obtained when the localization of the endogenous protein was analyzed in HeLa cells. However in this case the NPC substructures were not well preserved (data not shown). In conclusion, TAP preferentially associates with the peripheral structures of the NPC, in particular with the cytoplasmic fibrils and the nuclear baskets. This localization is very similar to that reported for Mex67p in yeast (Santos-Rosa et al., 1998) and it is consistent with the direct interaction of TAP with CAN and Nup98.

\section{The NPC-binding domain of TAP is necessary and sufficient for its targeting to the nuclear rim}

The nuclear-rim association domain of TAP was reported to reside within residues 412-619 (Bear et al., 1999). However this fragment includes both the p15and the nucleoporin-binding domains of TAP. To determine whether the nucleoporin-binding domain of TAP on its own was sufficient to mediate its interaction with the NPC in vivo, the subcellular localization of various TAP derivatives fused to the green fluorescent protein (GFP) was analyzed in HeLa cells. Figure 9 shows that the GFP-tagged wild-type protein exhibited the subcellular localization of endogenous TAP (Fig. 9 vs. Fig. $8 A, B)$. To visualize the rim staining, transfected cells were extracted with Triton $X-100$ prior to fixation (Fig. 9, +Triton X-100). The wild-type protein, the deletion mutant TAP $\Delta 437-507$, and fragments 371-619, 470-619, and 508-619 localized to the nuclear rim (Fig. 9). Deletion mutants TAP $\Delta 541-569$ and TAP $\Delta 567-$ 613 gave a very weak rim staining. In contrast, fragments 1-372, 371-551, and 540-619 were not detected at the nuclear envelope following Triton extraction. Note that TAP deletion mutants and fragment 1-372 entirely localize within the nucleoplasm because of the presence of the NLS at their N-terminus, whereas TAP C-terminal fragments, lacking the NLS, distribute evenly between the nuclear and cytoplasmic compartments, most likely because of their ability to interact with nucleoporins and translocate across the NPC.

In summary, fragments 470-619 and 508-619, which do not interact with $\mathrm{p} 15$, localize to the nuclear rim, whereas fragment $371-551$, which interacts with p15 (Fig. 7), was not detected at the nuclear rim. These observations, together with the results obtained with the deletion mutants, indicate that, in HeLa cells, binding to 15 is not required for the stable association of TAP with the NPC. In contrast, fragments 470-619 and 508-619, which interact with multiple nucleoporins in vitro, are sufficient for stable rim association in vivo. Thus, these fragments target TAP to the NPC in vivo, most likely by directly interacting with the FG-repeat domains of nucleoporins.

\section{The NPC-binding domain of TAP blocks multiple export pathways}

The experiments described above clearly establish that the C-terminal domain of TAP mediates its interaction 

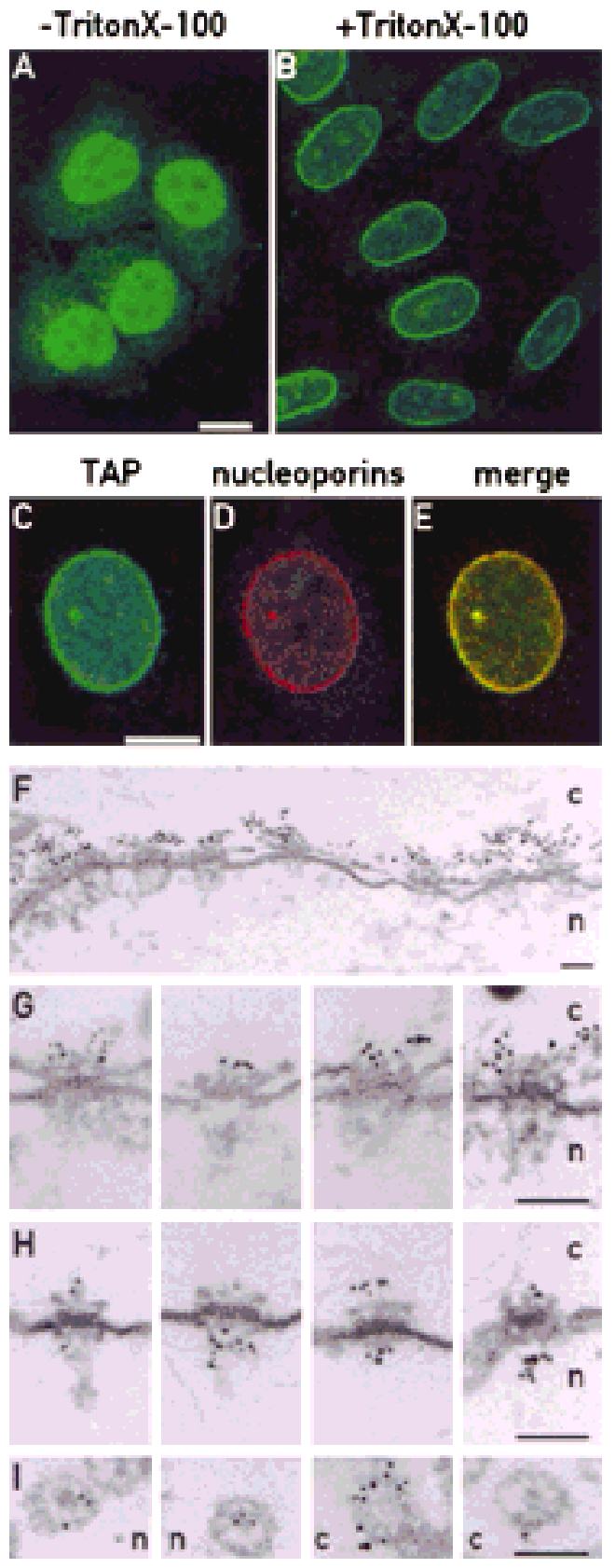

FIGURE 8. TAP localizes to the nucleoplasm and to both the nucleoplasmic and cytoplasmic faces of the NPC. A: HeLa cells were fixed in formaldehyde, permeabilized with Triton X-100 and immunostained with antibodies to TAP. TAP is predominantly detected throughout the nucleoplasm, excluding nucleoli. B: When cells are extracted with Triton X-100 prior to fixation, a punctuate labeling pattern is visible at the nuclear periphery. C,D,E: HeLa cells were extracted with Triton X-100 prior to fixation and coimmunostained with anti-TAP serum and a monoclonal antibody directed against nucleoporins. Under these conditions the anti-TAP antibodies stain a rim at the nuclear periphery $(\mathbf{C})$ which colocalizes with the labeling produced by the antinucleoporin antibody (D,E). Bar: $10 \mu \mathrm{m}$. F,G: Nuclear envelope cross sections and selected examples of immunogold-labeled nuclear pore cross sections from isolated Xenopus oocyte nuclei expressing zzTAP. H,I: Cross sections and tangential sections of immuno-gold-labeled nuclear pore complexes from Xenopus oocyte nuclei permeabilized with Triton X-100 prior to the incubation with the antibody. The anti-Protein A antibody labeled the cytoplasmic filaments and nuclear baskets of the NPC. The cytoplasmic (c) and nuclear (n) sides of the nuclear envelope are indicated. Scale bar: $100 \mathrm{~nm}$. with nucleoporins both in vitro and in vivo. Its role in the CTE-dependent export of U6 RNA (Fig. 1) and of unspliced pre-mRNA (Bear et al., 1999; Kang \& Cullen 1999) led us to hypothesize that this domain may bridge the interaction between specific RNP export substrates and the NPC during translocation. Thus, the NPCbinding domain of TAP may have a functional role similar to that of the NPC-binding domains of the $\beta$-like transport receptors. To test this hypothesis, and based on the observation that the NPC-binding domain of importin- $\beta$ blocks multiple transport pathways in a dominant negative manner (Kutay et al., 1997), we investigated whether the NPC-binding domain of TAP could interfere with nuclear transport processes. Purified recombinant TAP C-terminal fragments fused to GST (fragments 371-619, 371-551, 470-619, 508-619, and 540-619) were injected in Xenopus oocyte cytoplasm $1 \mathrm{~h}$ prior to their nuclear coinjection with a mixture of labeled RNAs. This mixture consisted of DHFR mRNA, Histone $\mathrm{H} 4 \mathrm{mRNA}, \mathrm{U} 1 \Delta \mathrm{Sm}, \mathrm{U} 5 \Delta \mathrm{Sm}, \mathrm{U} 6 \Delta \mathrm{ss}$, and the human initiator methionyl tRNA. Following a 3-h incubation, in control oocytes about $70 \%$ of the DHFR, $77 \%$ of the Histone $\mathrm{H} 4$ mRNA, $72 \%$ of the U1 snRNA, and $68 \%$ of the U5 snRNA moved to the cytoplasm (Fig. 10A, lanes 4-6) whereas tRNA export was complete (Fig. 10A, lanes 4-6). Injection of fragments 371619, 470-619, and 508-619 strongly inhibited export of all RNAs, and partially reduced tRNA export (Fig. 10A, lanes 7-9 and 13-18). In contrast, fragment 540-619 (Fig. 10A, lanes 19-21) and fragment 371-551, which binds p15 (Fig. 10A, lanes 10-12), had no effect.

Next we analyzed the effect of TAP fragments 371619 and 470-619 on the export of other RNAs. In particular, we were interested in determining whether these fragments could also inhibit nuclear export driven by the CTE or by the HIV-I RRE-Rev system. Purified recombinant TAP fragments were injected into Xenopus oocyte cytoplasm $1 \mathrm{~h}$ prior to their nuclear coinjection with a mixture of three labeled RNAs. This mixture consisted of U6 6 ss and $U 1 \Delta S m$ RNAs and of an adenovirus-derived precursor mRNA bearing the CTE (Ad-CTE) or the HIV-I RRE in the intron (Ad-RRE) (Fischer et al., 1995; Saavedra et al., 1997). Recombinant HIV Rev protein was included in the injection mixtures containing the Ad-RRE precursor RNA. Following $3 \mathrm{~h}$ of incubation, a substantial amount of the precursor RNA was spliced (Fig. 10B,C, lanes 4-6). About 65\% of the resulting mRNA and $61 \%$ of the U 1 snRNA and of the intron lariat bearing the CTE were found in the cytoplasmic fraction (Fig. 10B, lanes 4-6). Export of the intron lariat bearing the RRE was complete (Fig. 9C, lanes 4-6). Injection of fragment 371-619 did not affect splicing efficiency but strongly inhibited export of all RNA species analyzed (Fig. 10B,C, lanes 7-9). Fragment 470-619 also strongly blocked U1 snRNA, mRNA, and CTE-dependent nuclear export (Fig. 10B, lanes 10-12) whereas fragment 540-619 had no ef- 


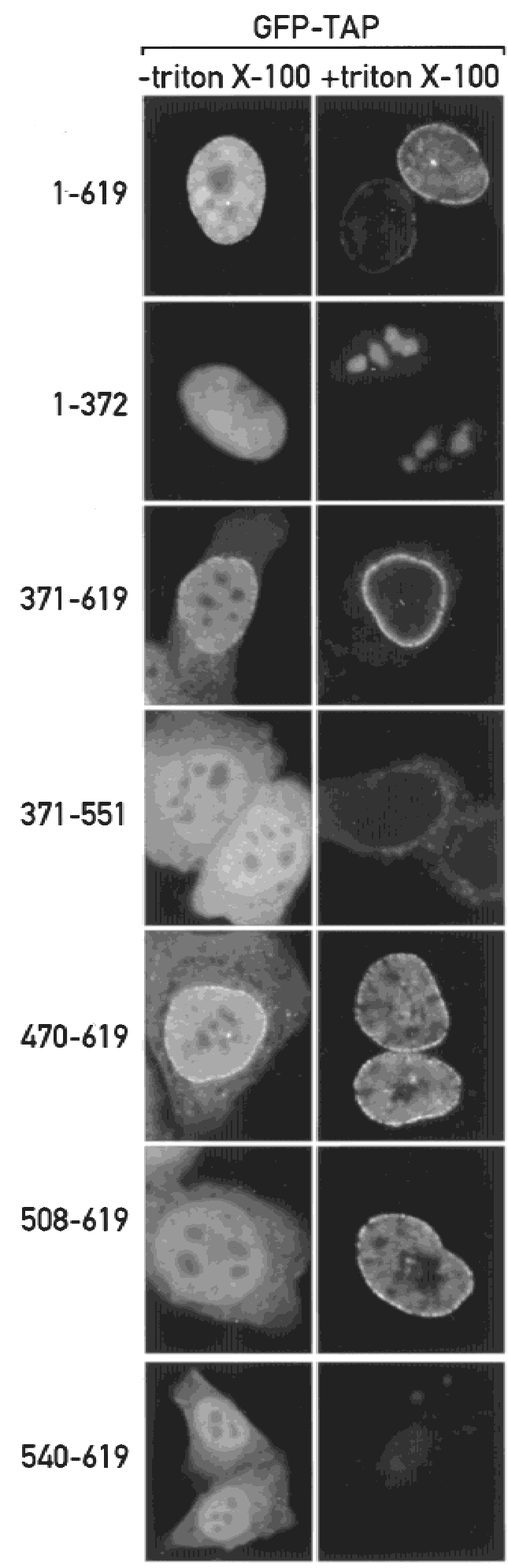

fect (Fig. 10B,C, lanes 13-15 and 10-12, respectively). Inhibition of export resulted in degradation of the nonspliced precursor RNA (Fig. 10B,C, lanes 7-9 and 10-12).

In summary, TAP fragments 470-619 and 508-619, which both localize to the nuclear rim in HeLa cells and interact with several FG-repeat-containing nucleopor-

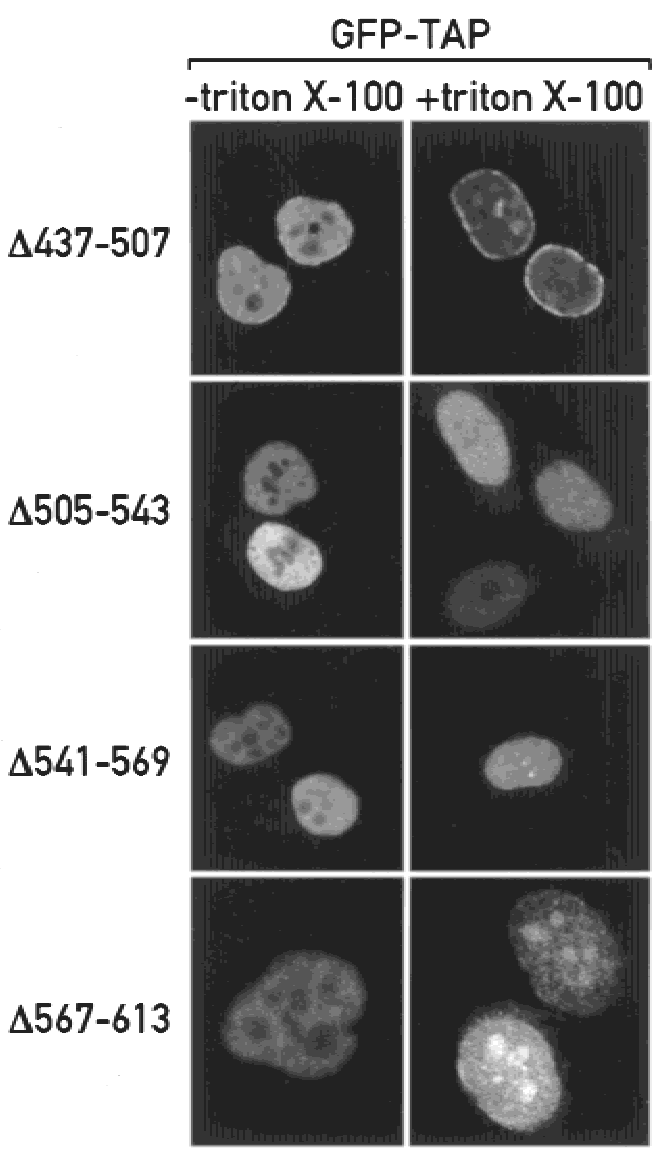

FIGURE 9. The NPC-binding domain of TAP localizes at the nuclear rim. HeLa cells were transfected with pEGFP-C1 TAP and several TAP fragments or TAP internal deletion mutants fused to GFP. Approximately $20 \mathrm{~h}$ after transfection, cells were fixed in formaldehyde and directly observed with the fluorescence microscope (left panels: - triton X-100) or extracted with Triton X-100 prior to fixation (right panels: +triton X-100). The nuclear rim staining is readily detected for TAP, TAP $\Delta 437-507$, and fragments $371-619,470-619$, and 508-619.

ins but not with p15, interfere with tRNA export and strongly inhibited CRM1-mediated export and the mRNA export pathway in Xenopus oocytes. This suggests that in vivo these fragments can compete with other transport receptors for binding sites on the NPC. Together, our observations provide strong evidence for a role of these fragments in mediating the association of TAP 


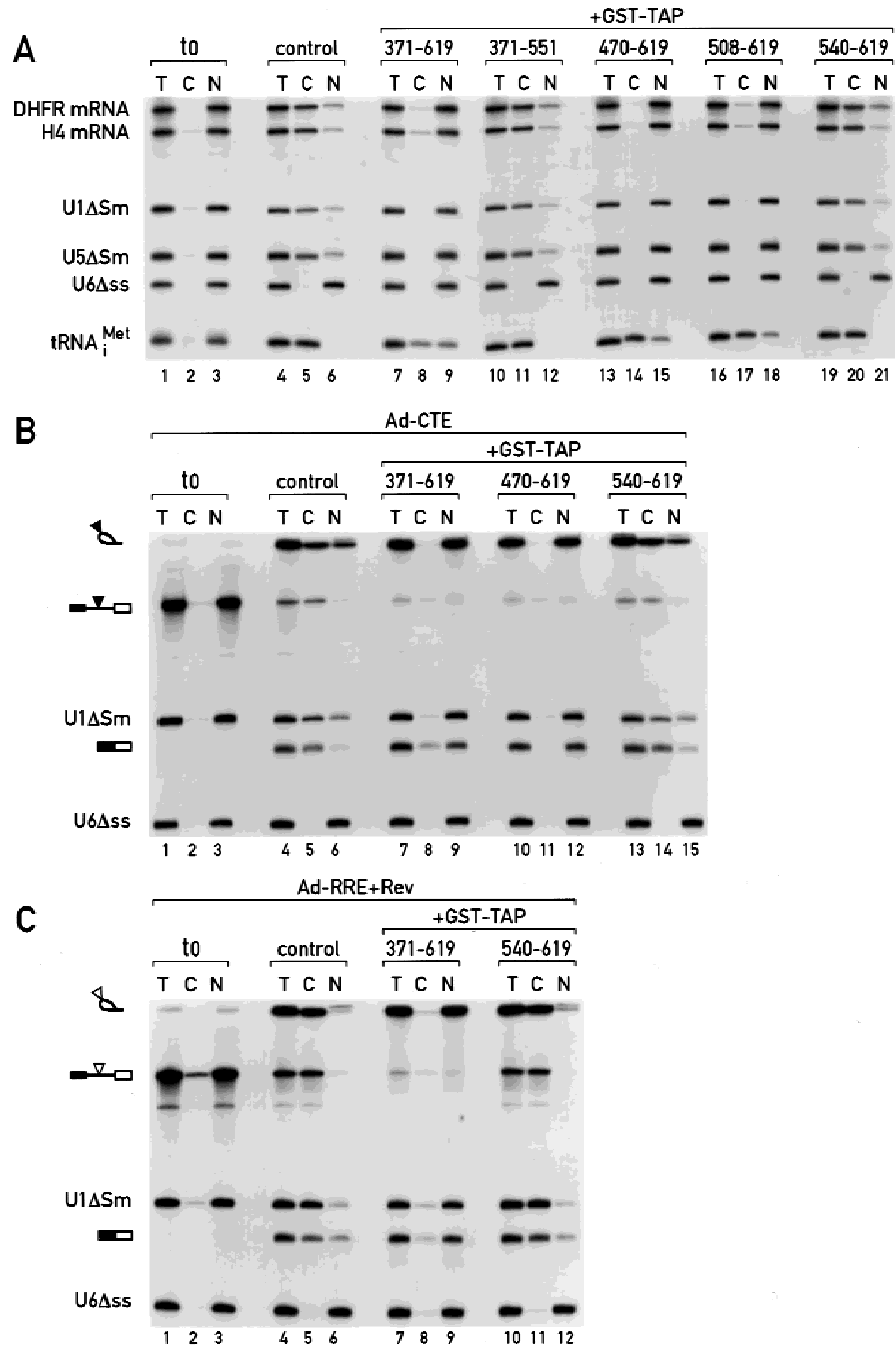

FIGURE 10. Inhibition of RNA nuclear export by the NPC-binding domain of TAP. A: Purified recombinant proteins indicated above the lanes were injected into the oocyte cytoplasm. After $1 \mathrm{~h}$ incubation, a second microinjection was performed into the oocyte nuclei with a mixture of radiolabeled RNAs. This mixture consisted of DHFR mRNA, Histone H4 mRNA, U1 $\Delta$ Sm, U5 $\Delta \mathrm{Sm}, \mathrm{U} 6 \Delta \mathrm{ss}$, and human initiator methionyl tRNA. RNA samples were collected $3 \mathrm{~h}$ after injection and analyzed as indicated in Figure 1B. B,C: Purified recombinant GST-TAP fragments indicated above the lanes were injected into the oocyte cytoplasm. After $1 \mathrm{~h}$ incubation, a second microinjection was performed into the oocyte nuclei with a mixture of in vitro transcribed ${ }^{32} \mathrm{P}$-labeled RNAs. This mixture consisted of U1 $\Delta$ Sm RNA, U6 $\Delta s$ RNA, and a precursor RNA containing the SRV-1 CTE (Ad-CTE, B) or the HIV RRE (Ad-RRE, C) inserted in the intron as indicated. Recombinant HIV Rev protein was coinjected with samples containing Ad-RRE precursor RNA. The concentration of Rev in the injected samples was $1 \mu \mathrm{M}$. RNA samples from total oocytes (lanes T), cytoplasmic (lanes C) and nuclear (lanes N) fractions were collected $3 \mathrm{~h}$ after injection, or immediately after injection (t0: lanes 1-3, B and C) and analyzed as described in Figure 1A. Symbols are as in Figure 1A. The open and filled triangles represent the RRE and the CTE, respectively. In all panels, one oocyte equivalent of RNA, from a pool of 10 oocytes, was loaded per lane. The concentration of the GST-TAP fragments in the injected samples was about $100 \mu \mathrm{M}$. 
with the NPC in vivo and thus define the NPC-targeting domain of TAP.

\section{TAP binding to nucleoporins but not to p15 is required to promote export of U6-CTE RNA}

Binding of TAP to nucleoporins appears to be relevant for its role in mediating CTE-dependent export of premRNAs and U6 RNA, as TAP deletion mutants impaired in nucleoporin binding (i.e., TAP1-610, 61-610) inhibit these export processes. Moreover, as these TAP mutants bind both p15 and Nup98, it appears that p15 and Nup98 binding by TAP are not sufficient to promote export of these RNAs. Proteins implicated in TAPmediated export of CTE-bearing substrates are expected to interact with TAP/CTE RNA complexes. We therefore tested the effect of the CTE RNA on the interaction of TAP with nucleoporins and p15. Surprisingly, binding of TAP to the CTE RNA prevented its interaction with p15 and with all nucleoporins tested with the exception of Nup98 (Fig. 11A). This result is consistent with the observation that different nucleoporins may have distinct modes of interaction with TAP. Furthermore, this result suggests that binding of the CTE RNA to TAP may produce an important conformational change in the protein that impedes its interaction with multiple partners including p15, CAN, and E1B-AP5. Therefore we hypothesized that these proteins are unlikely to play a role in the export of CTEbearing RNA substrates. To test this hypothesis we analyzed some of the TAP deletion mutants described in Figure 7 for their ability to stimulate CTE-dependent export of U6 RNA. In particular, we tested deletion mutants TAP $\Delta 22-53$, TAP $\Delta 430-550$, and TAP $\Delta 567-613$, which are impaired in binding to E1B-AP5, p15, and nucleoporins, respectively. We have also tested a TAP mutant having a deletion of the putative NES (TAP $\Delta 88-117)$. Figure 11B shows that TAP $\Delta 567-613$, like TAP1-610, failed to stimulate U6-CTE RNA export (lanes 16-21), whereas TAP $\Delta 430-550$ stimulates U6-

A

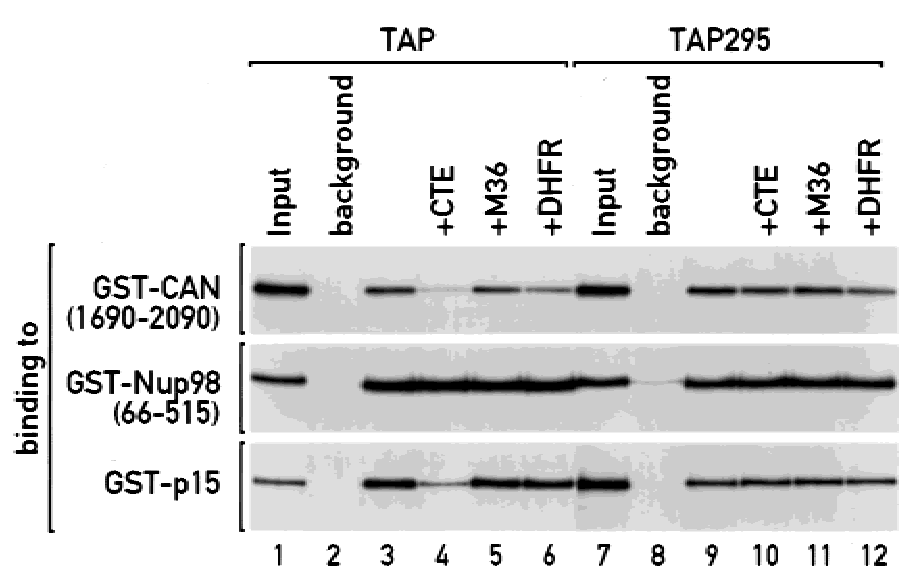

B

+GST-TAP [6uM]

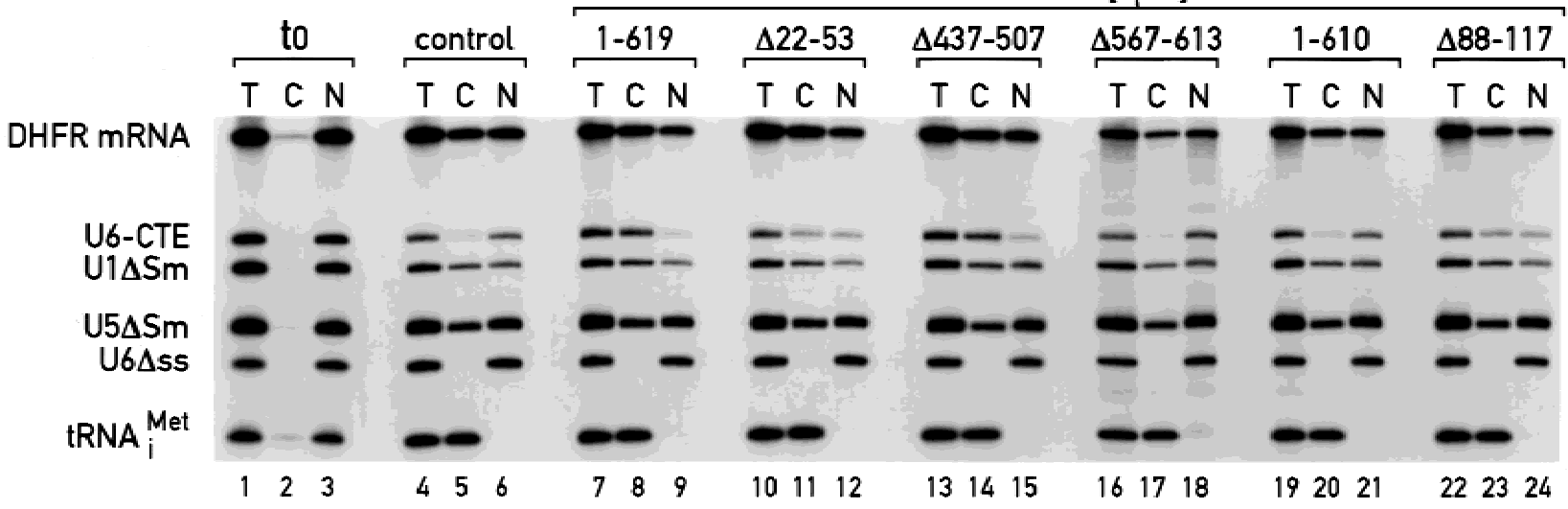

FIGURE 11. 15 binding to TAP is not required to promote export of CTE-bearing RNA substrates. A: GST pull-down assays were performed with ${ }^{35}$ S]methionine-labeled TAP or TAP mutant 295 and recombinant CAN, Nup98, and p15 expressed in E. coli as GST fusions. CTE, M36, and DHFR RNAs were added to the binding reactions as indicated. The concentration of the RNAs was $0.4 \mu \mathrm{M}$. One tenth of the inputs and one third of the bound fractions were analyzed on SDS-PAGE followed by fluorography. B: Purified recombinant proteins indicated above the lanes were injected into Xenopus oocyte nuclei together with a mixture of radiolabeled RNAs. This mixture consisted of DHFR mRNA, U6-CTE, U1 $\Delta$ Sm, U5 $\Delta$ Sm, U6 $\Delta$ ss RNAs, and human initiator methionyl tRNA. RNA samples were collected 90 min after injection, or immediately after injection (t0: lanes 1-3) and analyzed as indicated in Figure 1B. 
CTE export as efficiently as the full-length protein (Fig. 11B, lanes 13-15 vs. 7-9). Finally, mutants TAP $\Delta 22-53$ and TAP $\Delta 88-117$ stimulate U6-CTE RNA export but with a reduced efficiency compared to the wild-type protein (Fig. 11B, lanes 10-12 and 22-24). However, these proteins were able to quantitatively export U6-CTE RNA upon longer incubation times (data not shown).

In conclusion, our results show that p15 binding to TAP is not required to promote export of CTE RNA substrates whereas the nucleoporin-binding domain is strictly required to mediate CTE-dependent export of specific RNA substrates (i.e., U6 and pre-mRNAs). Among the nucleoporins analyzed in this study, CAN is unlikely to be involved in the export of TAP/CTE complexes as these complexes do not interact with the nucleoporin. In contrast, Nup98 may play a role in TAPmediated export of CTE-bearing RNAs. However, Nup98 binding is not sufficient to drive the complete export process. Therefore it is possible that other nucleoporins acting dowstream of Nup98 may be implicated. Note that the interactions that are not required for export of CTE-bearing RNA substrates may play a role in the export of cellular mRNAs, as their mode of interaction with TAP is distinct from that of the CTE-RNA.

\section{DISCUSSION}

We have shown previously that TAP mediates CTEdependent nuclear export by directly interacting with the CTE-RNA via its N-terminal domain (Grüter et al., 1998; Braun et al., 1999). Although the CTE-binding domain of TAP was shown to be sufficient to promote export of an excised intron lariat in Xenopus oocytes (Braun et al., 1999 and Fig. 1A), in avian and Xenopus cultured cells, the $\mathrm{C}$-terminal domain of TAP was also required for the export of a pre-mRNA (Bear et al., 1999; Kang \& Cullen, 1999). Here we show that the C-terminal domain of TAP is involved in the export of specific CTE-bearing RNA substrates. To investigate the mechanism by which both the CTE-binding domain and the C-terminal domain of TAP mediate RNA export at the molecular level we searched for TAP-interacting proteins. Using affinity chromatography, we identified several nucleoporins as putative TAP partners. These were RanBP2, CAN, Nup88, Nup93, p205, and Nup98. We show that binding of CAN or Nup98 by TAP is direct and mediated by the C-terminal domain of TAP and the FG-repeat domain of the nucleoporins. Aside from CAN and Nup98, the C-terminal domain of TAP (residues 508-619) interacts with multiple FG-repeat containing nucleoporins and therefore represents its NPC-binding domain. Indeed, in vivo this domain targets TAP to the NPC and interferes with multiple nuclear export pathways. Furthermore, transportin and two mRNAassociated proteins, hGle2 an E1B-AP5, previously implicated in mRNA export, were also selected on im- mobilized TAP. The interaction of TAP with multiple components of the NPC, its direct binding to CTE-bearing RNAs and its direct or indirect association with cellular mRNAs suggest that TAP mediates export of specific RNA substrates by bridging their interaction with the NPC during translocation.

\section{Is TAP a non- $\beta$-like nuclear transport receptor for mRNA?}

Cellular mRNAs are exported as large mRNPs. Their translocation through the NPC may require the establishment of multiple contacts with nucleoporins. This could be achieved by the presence of multiple copies of one export mediator or multiple export mediators along the mRNP. Although a contribution of $\beta$-like receptors to mRNP export cannot be ruled out, they are unlikely to account for all interactions with the NPC required for mRNA export, as the NPC-associated proteins TAP/Mex67p and hGle2/Gle2p play an important role in this process (reviewed by Doye \& Hurt, 1997; Mattaj \& Englmeier, 1998). These proteins exhibit several common properties. First, fractions of these proteins localize to both the nucleoplasmic and cytoplasmic faces of the NPC (Kraemer \& Blobel, 1997; SantosRosa et al., 1998; this work), suggesting that they interact with multiple components of the pore. Second, both proteins shuttle between the nuclear and cytoplasmic compartments (Bear et al., 1999; Kang \& Cullen, 1999; Katahira et al., 1999; I.C. Braun, J.P. Rodrigues, M. Carmo-Fonseca, \& E. Izaurralde, unpubl. results). Finally, both proteins bind mRNPs directly or indirectly (Kraemer \& Blobel, 1997; Grüter et al., 1998; SantosRosa et al., 1998; Braun et al., 1999; Kang \& Cullen, 1999; Katahira et al., 1999; Pritchard et al., 1999), and may therefore mediate $\mathrm{mRNP} / \mathrm{NPC}$ interactions during export. Consequently, TAP and Gle2 may fulfill the function of an mRNA nuclear export receptor distinct from the $\beta$-like family of Ran binding proteins.

\section{The C-terminal domain of TAP mediates its interaction with the NPC}

An expected property of a nuclear transport mediator is its ability to interact with components of the NPC (reviewed by Görlich, 1997; Mattaj \& Englmeier, 1998). In HeLa cells a fraction of TAP colocalizes with NPC markers at the nuclear rim (Figs. 8 and 9 and Bear et al., 1999; Katahira et al., 1999). By immunoelectron microscopy we have localized TAP to both the nuclear baskets and the cytoplasmic fibrils of the NPC (Fig. 8). When HeLa cell extracts were subjected to binding to immobilized TAP, we selected the nucleoporin Nup98 and three NPC subcomplexes (Fig. 2). Furthermore in vitro, TAP interacts with CAN, Nup98, p62, Nup153, and hCG1 (Fig. 7). Binding of TAP to the nucleoporins analyzed in this study is mediated 
by its C-terminal NPC-binding domain (residues 508 619, Fig. 7). In HeLa cells this domain was shown to be necessary and sufficient for the localization of TAP to the nuclear rim (Fig. 9). Furthermore, this domain is a potent inhibitor of mRNA and CRM1 export pathways indicating that, in vivo, it competes with other transport mediators for binding sites at the NPC (Fig. 10). Together these findings reveal multiple interactions between TAP and nucleoporins analogous to those described between nucleoporins and the transport receptors of the $\beta$-like family (Radu et al., 1995; Rexach \& Blobel, 1995; Neville et al., 1997). However, whereas the NPC/ $\beta$-like receptor interactions are regulated by Ran (Rexach \& Blobel, 1995; Askjaer et al., 1999; Kehlenbach et al., 1999; Nakielny et al., 1999), the mechanism by which TAP regulates its binding to the NPC are unknown.

The NPC-binding domain of TAP, like that of the $\beta$-like transport receptors, has the ability to shuttle between the nucleus and cytoplasm. Indeed, we and others have observed that the very $\mathrm{C}$-terminal domain of TAP (TAP540-619) shuttles (Bear et al., 1999; Braun et al., 1999; Kang \& Cullen, 1999). Furthermore, TAP C-terminal fragments, fused to GFP or to GST, can enter the nucleus (Fig. 9) (Bear et al., 1999; Kang \& Cullen, 1999; Katahira et al., 1999). The shuttling behavior of the C-terminal TAP fragment led Kang \& Cullen (1999) to propose that TAP has novel NLS and NES sequences at its $\mathrm{C}$-terminus. In contrast to this interpretation, Bear et al. (1999) concluded that the C-terminal domain of TAP does not contain bona fide NLS or NES but represents a nuclear rim-targeting domain. In agreement with Bear et al. (1999) we propose that the C-terminal domain of TAP represents its NPCbinding domain, which is likely to promote export without the aid of a $\beta$-like export receptor. Our findings provide new insight onto the mechanism by which the C-terminal domain of TAP promotes RNA nuclear export. However, the mechanism by which the isolated CTE-binding domain promotes export of CTE-bearing intron lariats remains to be established. A role of this domain in mediating CTE-dependent export of specific substrates is further supported by the observation that this domain shuttles between nucleus and cytoplasm (I.C. Braun, J.P. Rodrigues, M. Carmo-Fonseca, \& E. Izaurralde, unpubl. results).

It is intriguing that in spite of having an NPC-binding domain that can shuttle on its own, TAP has an NLS at its N-terminus (Bear et al., 1999; Kang \& Cullen, 1999; Katahira et al., 1999) that binds transportin and substantially contributes to TAP nuclear uptake (Fig. 4). Mutations that abrogate NLS activity result in an almost equal distribution of TAP between the nuclear and cytoplasmic compartments (Fig. 9; Bear et al., 1999; Katahira et al., 1999), most likely due to the shuttling behavior of its NPC-binding domain. Consequently, the $\mathrm{N}$-terminal NLS is responsible for the quantitative ac- cumulation of TAP within the nucleoplasm at steady state. Thus, binding of transportin increases the efficiency of TAP recycling back to the nucleus and may provide a mechanism for substrate release in the cytoplasm (see below).

\section{Substrate binding: TAP interacts with E1B-AP5, an hnRNP-like protein}

A second property of an export receptor is the ability to interact directly or indirectly with its substrate. TAP directly interacts with CTE-bearing RNA export substrates (Grüter et al., 1998; Braun et al., 1999; Kang \& Cullen 1999). Its mode of interaction with cellular mRNAs remains to be established, but is likely to be different from that with the CTE RNA for the following reasons. First, most cellular mRNAs do not contain sequences similar to those present in the CTE. Second, although TAP exhibits a low, nonspecific affinity for RNAs (Güter et al., 1998; Braun et al., 1999; Katahira et al., 1999), in vitro its affinity for the CTE RNA is approximately three orders of magnitude higher than that for the DHFR mRNA (Braun et al., 1999). Third, whereas an excess of CTE RNA saturates export of mRNAs, an excess of mRNA does not interfere with CTE export (Pasquinelli et al., 1997; Saavedra et al., 1997). Based on these observations, we have hypothesized that the CTE bypasses several steps in the mRNA export pathway and directly interacts with TAP, whereas cellular mRNAs may recruit TAP via protein-protein interactions. Consistent with this hypothesis is the observation that TAP directly stimulates CTE-dependent export but not the export of cellular mRNAs (Fig. 1), indicating that TAP is not limiting for mRNA export in Xenopus oocytes. In this study we show that TAP interacts with E1B-AP5. E1B-AP5 is related to hnRNP proteins (Gabler et al., 1998) and may therefore facilitate the recruitment of TAP by the mRNP. Independent of whether recruitment of TAP by the mRNP is direct or mediated by proteins such as E1B-AP5, the regulation of its interaction with mRNPs remains to be elucidated. E1B-AP5 is a good candidate regulator of these interactions, as some of its functions may be modulated by nucleotide binding and hydrolysis (Gabler et al., 1998). Interestingly, Mex67p also interacts with an hnRNP-like protein, Yral, suggesting that in yeast, Mex67p may be recruited to the mRNP complexes via protein-protein interactions (A. Bachi \& E. Izaurralde, unpubl.).

\section{TAP recycling}

After translocating their cargoes through the NPC, transport receptors are dissociated from their substrates and are recycled to initiate additional rounds of transport. As mentioned above, one possibility is that binding of transportin on the cytoplasmic side of the pore would 
promote the dissociation of TAP from its substrate and promote its recycling back to the nucleus. This mechanism may not function when TAP exports CTE-bearing RNA substrates (Fig. 5). Alternatively, Dbp5, a DEADbox protein essential for mRNA export, may also play an important role in disrupting $\mathrm{mRNA} /$ protein interactions as the mRNP emerges from the NPC (SnayHodge et al., 1998; Tseng et al., 1998; Schmitt et al., 1999). Consistent with this is the observation that Dbp5 dominant negative mutants block nuclear export of mRNAs and of CTE-bearing RNAs in Xenopus oocytes (Schmitt et al., 1999). Understanding the mechanism by which TAP mediates directional transport of RNA substrates across the NPC is an important goal for the future.

\section{MATERIALS AND METHODS}

\section{Plasmids, recombinant protein expression, and purification}

All TAP constructs were cloned into the $\mathrm{Ncol}$ and $\mathrm{BamHI}$ sites of the pGEXCS vector. TAP truncation 61-610 was originally obtained in our laboratory as a result of a fortuitous PCR-mutation that created a BamHI site at residue 610. GST fusions were expressed in E. coli BL21(DE3) pLysS and purified as described by Grüter et al. (1998). Alanine scan mutants of TAP were previously described (Braun et al., 1999). TAP deletion mutants were generated by combining fragments from different alanine scan mutants. RanQ69L was prepared as described by Görlich et al. (1996). Transportin was expressed in E. coli and purified as described by Izaurralde et al. (1997). For expression in HeLa cells, TAP full-length cDNA and fragments were excised from the corresponding pGEXCS-TAP plasmid as Narl-BamHI fragments and cloned within the AcCl-BamHI sites of vector pEGFP-C1 (Clontech). Full-length human Nup93, hGle2, and p15 cDNAs were obtained by PCR using Expand ${ }^{\mathrm{TM}}$ high fidelity enzyme (Roche), with human HeLa cDNA as a template (Clontech) and primers containing the appropriate restriction sites. Nup93 was cloned into the BamHI-Hindlll sites of pBSpAlter, a derivative of pALTER-Ex1 (Promega); hGle2 was cloned into the Nhel-BamHI sites of vector pRSETA (Invitrogen). p15 was cloned into the EcoRI-BamHI sites of pBS-SK- $\beta$-globin$\mathrm{HA}$, a derivative of $\mathrm{pBS}-\mathrm{SK}$ vector kindly provided by $\mathrm{Dr}$. Lionel Arnaud. Full-length CAN cDNA (pBS-KS-T7-CAN) was kindly provided by Dr. Gerard Grosveld. A fragment of CAN encompassing residues 1-1058 was obtained by PCR using plasmid pBS-KS-T7-CAN as template. The PCR fragment was cloned into the Ndel-EcoRI sites of the pRSETB vector (Invitrogen). Plasmids pGEX4T-CAN(1690-2090), pGEX4TCAN(1690-1894), and pBS-pALTER-hCG1 were provided by Dr. Françoise Stutz. CAN fragments encompassing residues 1690-1894 and 1983-2090 were excised from the pGEX4T constructs and cloned into the BamHI-Notl sites of the pRN3zz vector (see below). pT7-UTR-hCRM1 plasmid was kindly provided by Dr. Maarten Fornerod. pSVK3-fluE1B-AP5 was provided by Dr. Thomas Dobner. Nup98 cDNA was provided by Dr. Barbara Felber and cloned into the NcolNotl sites of a derivative of pRN3 (Lemaire et al., 1995).
pcDNA3-Nup84 (CP453) plasmid containing Nup88/Nup84 rat CDNA and Nup153 cDNA were provided by Dr. Ricardo Bastos. pBS-KS-p62 was provided by Dr. Volker Cordes. Plasmid pBSII-TKS-RanBP2 was provided by Dr. Takeharu Nishimoto.

\section{Antibodies}

The anti-TAP serum has been described before (Braun et al., 1999). Antibodies against human CRM1, human CAN, hGle2, and Nup98 were kindly provided by Drs. Maarten Fornerod, Gerard Groosvelt, Günter Blobel, and Aurelian Radu, respectively. Monoclonal antibody mAb422 to nucleoporins was kindly provided by Dr. Laura Davis.

\section{Immunofluorescence in HeLa cells}

Indirect immunofluorescence on HeLa cells was performed as previously described (Almeida et al., 1998). Cells were either fixed with $3.7 \%$ formaldehyde for $10 \mathrm{~min}$ and subsequently permeabilized with $0.5 \%$ Triton $\mathrm{X}-100$, or extracted first with $0.5 \%$ Triton X-100 for 3 min and then fixed in formaldehyde. Anti-TAP serum was diluted to 1:500. Doublelabeling experiments were performed using $\mathrm{mAb} 422$ directed against nucleoporins.

\section{Immunoelectron microscopy in Xenopus oocytes}

For immunoelectron microscopy, 8-nm diameter gold particles were prepared and an anti-Protein A antibody (Sigma, St. Louis, Missouri, USA) was directly conjugated to the colloidal gold particles as described by Panté et al. (1994). Localization of TAP was performed in Xenopus oocytes by preembedding labeling as described by Schmitt et al. (1999).

\section{Selection of HeLa cell nuclear proteins on immobilized TAP}

HeLa cell nuclear extracts (4 mg of total protein) prepared as described by Dignam et al. (1983) were incubated for $1 \mathrm{~h}$ at $4{ }^{\circ} \mathrm{C}$ with $20 \mu \mathrm{L}$ of IgG-Sepharose beads (Pharmacia) on which $10 \mu \mathrm{g}$ of zzTAP6xHis was previously immobilized. Incubations were performed in a final volume of $100 \mu \mathrm{L}$ of low-salt binding buffer (100 mM KCl, $20 \mathrm{mM}$ HEPES-KOH, $\mathrm{pH}$ 7.9, $0.2 \mathrm{mM}$ EDTA, $0.1 \mathrm{mM}$ DTT, 20\% glycerol), or the same buffer containing $1 \mathrm{M} \mathrm{KCl}$ (high salt). Beads were rotated for $1 \mathrm{~h}$ at $4{ }^{\circ} \mathrm{C}$, recovered by gentle centrifugation and washed six times with $200 \mu \mathrm{L}$ of ice-cold binding buffer containing $200 \mathrm{mM} \mathrm{KCl}$. Bound proteins were eluted with SDSsample buffer without $\beta$-mercaptoethanol. Beads were pelleted by centrifugation, the supernatants were collected, supplemented with $\beta$-mercaptoethanol, and analyzed by SDS-PAGE followed by silver staining. When indicated, $10 \mu \mathrm{g}$ of RanQ69L and $1 \mathrm{mM}$ GTP were included in the binding reactions. In the experiment shown in Figure 2, TAP61-619 was used.

\section{Protein identification}

Proteins eluted from the affinity columns were analyzed on SDS-PAGE followed by silver staining. Bands of interest were 
excised and in-gel digested with trypsin (Shevchenko et al., 1996). Three tenths of a microliter of the total digest solution was analyzed by peptide mass mapping on a Bruker REFLEX MALDI time-of-flight mass spectrometer (Bruker-Franzen, Bremen, Germany) using the fast evaporation technique for matrix preparation (Vorm et al., 1994). A nonredundant protein database containing more than 300,000 entries was searched with the peptide masses. In cases when the identification was not certain, the peptide mixture was extracted, desalted on a 100-nL Poros R2 column, eluted directly into a nano electrospray needle, and analyzed on a triple quadrupole tandem mass spectrometer (API III, PE-Sciex, Ontario, Canada; Wilm et al., 1996). Proteins were identified using the sequence tag algorithm and the PeptideSearch program (Mann \& Wilm, 1994). Tandem MS experiments were carried on a triple quadrupole mass spectrometer (API III, PE-Sciex).

\section{In vitro translation}

For generation of $\left[{ }^{35} \mathrm{~S}\right]$-labeled in vitro-translated proteins, the combined in vitro transcription/translation (TnT) kit from Promega was used. Reactions were carried out at $30^{\circ} \mathrm{C}$ for $2 \mathrm{~h}$. Translation was checked by SDS-PAGE and subsequent fluorography using intensifying solutions from Amersham (Amplify). In vitro-translated proteins were directly used in binding assays without further purification.

\section{In vitro import assay}

TAP was labeled in $2.5 \times$ PBS buffer with an equimolar amount of alexa-5-maleimide (dissolved in water). The labeling reaction was carried out on ice for $3 \mathrm{~h}$. Nonincorporated label was removed by gel filtration on a NAP5 column (Pharmacia) equilibrated with $2.5 \times$ PBS, $250 \mathrm{mM}$ sucrose. Import reactions in permeabilized Hela cells were performed as described by Görlich et al. (1996, 1997). The import buffer included $2 \mathrm{mg} / \mathrm{mL}$ nucleoplasmin core to block unspecific binding, $20 \mathrm{mM}$ HEPES/KOH, pH 7.5, $120 \mathrm{mM}$ potassium acetate, $250 \mathrm{mM}$ sucrose, $0.5 \mathrm{mM}$ EGTA. The energy regenerating system contained $0.5 \mathrm{mM}$ GTP, $0.5 \mathrm{mM}$ ATP, $10 \mathrm{mM}$ creatine phosphate and $50 \mu \mathrm{g} / \mu \mathrm{L}$ creatine kinase. The Ran mix consisted of $3 \mu \mathrm{M}$ Ran-GDP, $0.3 \mu \mathrm{M}$ NTF2, $0.3 \mu \mathrm{M}$ RanBP1, and $0.2 \mu \mathrm{M}$ Rna1p.

\section{Pull-down assays}

Unless indicated otherwise, $5 \mu \mathrm{g}$ of GST-tagged recombinant protein immobilized on $20 \mu \mathrm{L}$ of packed glutathione agarose beads was used per binding reaction. Following binding of GST-tagged recombinant proteins, beads were washed twice with $0.5 \mathrm{~mL}$ of IPP buffer $(10 \mathrm{mM}$ Tris- $\mathrm{HCl}$, $\mathrm{pH} 8.0$, $50 \mathrm{mM} \mathrm{NaCl}$ ) supplemented with $1 \%$ Triton X-100, and twice with $0.5 \mathrm{~mL}$ of binding buffer (200 mM KCl, $20 \mathrm{mM}$ HEPES$\mathrm{KOH}, \mathrm{pH}$ 7.9, $0.2 \mathrm{mM}$ EDTA, $0.1 \mathrm{mM}$ DTT, 20\% glycerol). Between 2 and $5 \mu \mathrm{L}$ of in vitro-synthesized proteins were used per binding reaction in a final volume of $200 \mu \mathrm{L}$ of binding buffer containing $0.1 \%$ BSA. Binding was for $1 \mathrm{~h}$ at $4{ }^{\circ} \mathrm{C}$. Beads were washed four times with $0.5 \mathrm{~mL}$ of binding buffer. Bound proteins were eluted with SDS-sample buffer and analyzed by SDS-PAGE followed by fluorography. When indicated, $10 \mu \mathrm{g}$ of RanQ69L-GTP and $1 \mathrm{mM}$ GTP were added per binding reaction. In vitro binding assays with Protein A-tagged proteins were performed under the same conditions using IgG-Sepharose beads. In the experiment shown in Figure 4B, zzTAP was crosslinked to the beads and was therefore not present in the eluates.

\section{Xenopus laevis oocyte microinjections and RNA analysis}

DNA templates for in vitro RNA synthesis of Ad-CTE, AdRRE, DHFR mRNA, histone $\mathrm{H} 4 \mathrm{mRNA}, \mathrm{U} 5 \Delta \mathrm{Sm}, \mathrm{U} 1 \Delta \mathrm{Sm}$, and U6 6 ss RNAs, and human methionyl tRNA have been previously described (Saavedra et al., 1997). To generate U6-CTE template, human U6 snRNA was amplified by PCR and cloned as a $\mathrm{Xbal}$-BamHI fragment into pBSKS + (Stratagene), whereas the SRV-1 CTE was inserted into the BamHIXhol sites of this plasmid. The resulting construct was linearized by Xhol and transcribed with T7 RNA polymerase.

Synthesis of Ad-CTE, Ad-RRE, DHFR mRNA, histone H4 mRNA, U5 $\Delta \mathrm{Sm}$, and $\mathrm{U} 1 \Delta \mathrm{Sm}$ were primed with the $\mathrm{m}^{7} \mathrm{GpppG}$ cap dinucleotide, whereas synthesis of U6-CTE and U6 $\Delta \mathrm{ss}$ RNAs was primed with $\gamma$-mGTP. Oocyte injections and analysis of microinjected RNA by denaturing gel electrophoresis and autoradiography analysis were performed as previously described (Saavedra et al., 1997). The concentration of recombinant proteins in the injected samples are indicated in the figure legends.

\section{ACKNOWLEDGMENTS}

We are indebted to Patric Grüter, who performed the initial selections of TAP partners. The technical support of Emmanuelle Rohrbach is gratefully acknowledged. We wish to thank Lionel Arnaud, Ricardo Bastos, Günter Blobel, Volker Cordes, Mary Dasso, Laura Davis, Thomas Dobner, Valérie Doye, Barbara Felber, Maarten Fornerod, Gerard Grosveld, Takeharu Nishimoto, Aurelian Radu, and Françoise Stutz for their kind gift of the various cDNAs and antibodies used in this study. We thank Drs. Peter Duncan, Jacqueline FischerLougheed, and Jeffrey Patton for critical reading of the manuscript, and Nicolas Röggli for the photographic work. We are grateful to Drs. Miguel Lafarga and Maria Teresa Berciano for their precious help. This study was supported by the Junta Nacional de Investigação Científica e Técnologica (Programme PRAXIS XXI) Portugal, the German Ministry of Research and Technology (BMBF), the Swiss National Science Foundation, the State of Geneva and the Human Frontier Science Program Organisation.

Received September 9, 1999; returned for revision October 19, 1999; revised manuscript received October 27, 1999

\section{REFERENCES}

Almeida F, Saffrich R, Ansorge W, Carmo-Fonseca M. 1998. Microinjection of anti-coilin antibodies affects the structure of coiled bodies. J Cell Biol 142:899-912.

Askjaer P, Bachi A, Wilm M, Bischoff FR, Weeks DL, Ogniewski V, Ohno M, Kjems J, Mattaj IW, Fornerod M. 1999. RanGTP-regulated interactions of CRM1 with nucleoporins and a shuttling DEADbox helicase. Mol Cell Biol 19:6276-6285. 
Bailer SM, Siniossoglou S, Podtelejnikov A, Hellwig A, Mann M, Hurt E. 1998. Nup116p and Nup100p are interchangeable through a conserved motif which constitutes a docking site for the mRNA transport factor Gle2p. EMBO J 17:1107-1119.

Bear J, Tan W, Zolotukhin AS, Tabernero C, Hudson EA, Felber BK. 1999. Identification of novel import and export signals of human TAP, the protein that binds to the CTE element of the type $D$ retrovirus mRNAs. Mol Cell Biol 19:6306-6317.

Bharathi A, Ghosh A, Whalen WA, Yoon JH, Pu R, Dasso M, Dhar R. 1997. The human RAE1 gene is a functional homologue of Schizosaccharomyces pombe rae1 gene involved in nuclear export of Poly (A)+ RNA. Gene 198:251-258.

Bischoff FR, Krebber H, Kempf T, Hermes I, Ponstingl H. 1995a. Human RanGTPase activating protein RanGAP1 is a homolog of yeast RNA1p involved in messenger RNA processing and transport. Proc Natl Acad Sci USA 92:1749-1753.

Bischoff FR, Krebber H, Smirnova E, Dong WH, Ponstingl H. 1995b. Coactivation of RanGTPase and inhibition of GTP dissociation by Ran GTP binding protein RanBP1. EMBO J 14:705-715.

Boelens WC, Palacios I, Mattaj IW. 1995. Nuclear retention of RNA as a mechanism for localization. RNA 1:273-283.

Bogerd HP, Echarri A, Ross TM, Cullen BR. 1998. Inhibition of HIV-1 Rev and HTLV-I Rex function, but not MPMV CTE activity, by a mutant human nucleoporin targeted to Crm1. J Virol 72:86278635.

Braun IC, Rohrbach E, Schmitt C, Izaurralde E. 1999. TAP binds to the constitutive transport element (CTE) through a novel RNAbinding motif that is sufficient to promote CTE-dependent RNA export from the nucleus. EMBO $J$ 18:1953-1965.

Brown JA, Bharathi A, Ghosh A, Whalen W, Fitzgerald E, Dhar R. 1995. A mutation in the Schizosaccharomyces pombe rae1 gene causes defects in poly $(\mathrm{A})(+)$ RNA export and in the cytoskeleton. J Biol Chem 270:7411-7419.

Dahlberg JE, Lund E. 1998. Functions of the GTPase Ran in RNA export from the nucleus. Curr Opin Cell Biol 10:400-408.

Dignam J, Lebowitz R, Roeder R. 1983. Accurate transcription initiation by RNA polymerase II in a soluble extract from mammalian nuclei. Nucleic Acids Res 11:1475-1489.

Doye V, Hurt E. 1997. From nucleoporins to nuclear pore complexes. Curr Opin Cell Biol 9:401-411.

Fischer U, Huber J, Boelens WC, Mattaj IW, Lührmann R. 1995. The HIV-1 Rev activation domain is a nuclear export signal that accesses an export pathway used by specific cellular RNAs. Cell 82:475-483.

Fornerod M, Ohno M, Yoshida M Mattaj IW. 1997a. CRM1 is an export receptor for leucine-rich nuclear export signals. Cell 90: $1051-1060$.

Fornerod M, van Deursen J, van Baal S, Reynolds A, Davis D, Murti KG, Fransen J, Grosveld G. 1997b. The human homologue of yeast Crm1 is in a dynamic subcomplex with CAN/Nup214 and a novel nuclear pore component Nup88. EMBO J 16:807-816.

Fukuda M, Asano S, Nakamura T, Adachi M, Yoshida M, Yanagida M, Nishida E. 1997. CRM1 is responsible for intracellular transport mediated by the nuclear export signal. Nature 390:308-311.

Gabler S, Schüttt H, Groitl P, Wolf H, Shenk T, Dobner T. 1998. E1B 55-kilodalton-associated protein: A cellular protein with RNAbinding activity implicated in nucleocytoplasmic transport of adenovirus and cellular mRNAs. J Virol 72:7960-7971.

Görlich D. 1997. Nuclear protein import. Curr Opin Cell Biol 9:412-419.

Görlich D, Dabrowski M, Bischoff FR, Kutay U, Bork P, Hartmann E, Prehn S, Izaurralde E. 1997. A novel class of Ran-GTP binding proteins. J Cell Biol 138:65-80.

Görlich D, Panté N, Kutay U, Aebi U, Bischoff FR. 1996. Identification of different roles for RanGDP and RanGTP in nuclear protein import. EMBO J 15:5584-5594.

Grandi P, Dang T, Panté N, Shevchenko A, Mann M, Forbes D, Hurt E. 1997. Nup93, a vertebrate homologue of yeast Nic96p, forms a complex with a novel $205-\mathrm{kDa}$ protein and is required for correct nuclear pore assembly. Mol Cell Biol 8:2017-2038.

Grüter P, Tabernero C, von Kobbe C, Schmitt C, Saavedra C, Bachi A, Wilm M, Felber BK, Izaurralde E. 1998. TAP, the human homologue of Mex67p, mediates CTE-dependent RNA export from the nucleus. Mol Cell 1:649-659.

Izaurralde E, Kutay U, von Kobbe C, Mattaj IW, Görlich D. 1997. The asymmetric distribution of the constituents of the Ran system is essential for transport into and out of the nucleus. EMBO $J$ 16:6535-6547.

Kang Y, Cullen BR. 1999. The human TAP protein is a nuclear mRNA export factor that contains novel RNA-binding and nucleocytoplasmic transport sequences. Genes \& Dev 13:1126-1139.

Katahira J, Sträßer K, Podtelejnikov A, Mann M, Jung JU, Hurt E. 1999. The Mex67p-mediated nuclear mRNA export pathway is conserved from yeast to human. EMBO J 18:2593-2609.

Kehlenbach RH, Dickmanns A, Kehlenbach A, Guan T, Gerace, L. 1999. A role for RanBP1 in the release of CRM1 from the nuclear pore complex in a terminal step of nuclear export. J Cell Biol 145:645-657.

Klebe C, Bischoff FR, Ponstingl H, Wittinghofer A. 1995. Interaction of the nuclear GTP-binding protein Ran with its regulatory proteins RCC1 and RanGAP1. Biochemistry 34:639-647.

Kraemer D, Blobel G. 1997. mRNA binding protein mrnp 41 localizes to both nucleus and cytoplasm. Proc Natl Acad Sci USA 94:91199124.

Kutay U, Izaurralde E, Bischoff FR, Mattaj IW, Görlich D. 1997. Dominant-negative mutants of importin- $\beta$ block multiple pathways of import and export through the nuclear pore complex. EMBO J 16:1153-1163.

Mahajan R, Delphin C, Guan T, Gerace L, Melchior F. 1997. A small ubiquitin-related polypeptide involved in targeting RanGAP1 to nuclear pore complex protein RanBP2. Cell 88:97-107.

Mann M, Wilm M. 1994. Error-tolerant identification of peptides in sequence databases by peptide sequence tags. Anal Chem 66:4390-4399.

Mattaj IW, Englmeier L. 1998. Nucleocytoplasmic transport: The soluble phase. Annu Rev Biochem 67:256-306.

Matunis MJ, Coutavas E, Blobel G. 1996. A novel ubiquitin-like modification modulates the partitioning of the Ran-GTPase-activating protein RanGAP1 between the cytosol and the nuclear pore complex. J Cell Biol 135:1457-1470.

Murphy R, Watkins JL, Wente SR. 1996. GLE2, a Saccharomyces cerevisiae homologue of the Schizosaccharomyces pombe export factor RAE1, is required for nuclear pore complex structure and function. Mol Biol Cell 7:1921-1937.

Nakielny S, Dreyfuss G. 1997. Nuclear export of proteins RNAs. Curr Opin Cell Biol 9:420-429.

Nakielny S, Shaikh S, Burke B, Dreyfuss G. 1999. Nup153 is an M9-containing mobile nucleoporin with a novel Ran-binding domain. EMBO J 18:1982-1995.

Neville M, Lee L, Stutz F, Davis LI, Rosbash M. 1997. Evidence that the Importin-beta family member Crm1p bridges the interaction between Rev the nuclear pore complex during nuclear export in S. cerevisiae. Curr Biol 7:767-775.

Otero GC, Harris ME, Donello JE, HopeTJ. 1998. Leptomycin B inhibits Equine Infectious Anemia virus Rev Feline Immunodeficiency virus Rev function but not the function of the Hepatitis B virus posttranscriptional regulatory element. $J$ Virol 72:7593-7597.

Panté N, Bastos R, McMorrow I, Burke B, Aebi U. 1994. Interactions three-dimensional localization of a group of nuclear pore complex proteins. J Cell Biol 126:603-617.

Paraskeva E, Izaurralde E, Bischoff FR, Huber J, Kutay U, Hartmann E, Lührmann R, Görlich D. 1999. CRM1-mediated recycling of snurportin 1 to the cytoplasm. J Cell Biol 145:255-264.

Pasquinelli AE, Ernst RK, Lund E, Grimm C, Zapp ML, Rekosh D, Hammarskjold M-L, Dahlberg JE. 1997. The constitutive transport element (CTE) of Mason-Pfizer Monkey Virus (MPMV) accesses an RNA export pathway utilized by cellular messenger RNAs. EMBO J 16:7500-7510.

Pollard VW, Michael WM, Nakielny S, Siomi M, Wang F, Dreyfuss G. 1996. A novel receptor-mediated nuclear protein import pathway. Cell 86:985-994.

Pritchard CEJ, Fornerod M, Kasper LH, van Deursen JMA. 1999. RAE1 is a shuttling mRNA export factor that binds to a GLEBSlike NUP98 motif at the nuclear pore complex through multiple domains. J Cell Biol 145:237-253.

Radu A, Moore MS, Blobel G. 1995. The peptide repeat domain of nucleoporin Nup98 functions as a docking site in transport across the nuclear pore complex. Cell 81:215-222.

Rexach M, Blobel G. 1995. Protein import into nuclei: Association and dissociation reactions involving transport substrate, transport factors, and nucleoporins. Cell 83:683-692. 
Richards SA, Carey KL, Macara IG. 1997. Requirement of guanosine triphosphate-bound Ran for signal-mediated nuclear protein export. Science 276:1842-1844.

Saavedra C, Felber BK, Izaurralde E. 1997. The simian retrovirus-1 constitutive transport element CTE, unlike HIV-1 RRE, utilizes factors required for cellular RNA export. Curr Biol 7:619-628.

Saitoh H, Pu R, Cavenagh M, Dasso M. 1997. RanBP2 associates with Ubc9p and a modified form of RanGAP1. Proc Natl Acad Sci USA 94:3736-3741.

Santos-Rosa H, Moreno H, Simos G, Segref A, Fahrenkrog B, Panté B, Hurt E. 1998. Nuclear mRNA export requires complex formation between Mex67p and Mtr2p at the nuclear pores. Mol Cell Biol 18:6826-6838.

Schmitt C, von Kobbe C, Bachi A, Panté N, Boscheron C, Rodrigues JP, Rigaut G, Wilm M, Fonseca M-C, Séraphin B, Izaurralde E. 1999. Dbp5, a DEAD box-protein required for mRNA export, is recruited to the cytoplasmic fibrils of nuclear pore complex via a conserved interaction with CAN/Nup159p. EMBO J 18:43324347.

Segref A, Sharma K, Doye V, Hellwig A, Huber J, Lührmann R, Hurt E. 1997. Mex67p, a novel factor for nuclear mRNA rexport binds to both poly $(\mathrm{A})+$ RNA and nuclear pores. EMBO J 16:32563271.

Shevchenko A, Wilm M, Vorm O, Mann M. 1996. Mass spectrometric sequencing of proteins from silver-stained polyacrylamide gels. Anal Chem 68:850-858.

Siomi H, Dreyfuss G. 1995. A nuclear localization domain in the hnRNP A1 protein. J Cell Biol 129:551-560.

Siomi MC, Eder PS, Kataoka N, Wan L, Liu Q, Dreyfuss G. 1997. Transportin-mediated nuclear import of heterogenous nuclear RNP proteins. J Cell Biol 138:1181-1192.

Snay-Hodge CA, Colot HV, Goldstein AL, Cole CN. 1998. Dbp5p/
Rat8p is a yeast nuclear pore-associated DEAD-box protein essential for RNA export. EMBO J 17:2663-2676.

Stade K, Ford CS, Guthrie C, Weis K. 1997. Exportin 1 (Crm1p) is an essential nuclear export factor. Cell 90:1041-1050.

Tseng SS-I, Weaver PL, Hitomi M, Tartakoff AM, Chang T-H. 1998. Dbp5p a cytosolic RNA helicase, is required for poly $(A)+$ RNA export. EMBO J 17:2651-2662.

Vankan P, McGuigan C, Mattaj IW. 1992. Domains of U4 and U6 snRNAs required for snRNP assembly and splicing complementation in Xenopus oocytes. EMBO J 11:335-342.

Vorm O, Roepstorff P, Mann M. 1994. Improved resolution and very high sensitivity in MALDI TOF of matrix surfaces made by fast evaporation. Anal Chem 66:3281-3287.

Wilm M, Shevchenko A, Houthaeve T, Breit S, Schweigerer L, Fotsis T, Mann M. 1996. Femtomole sequencing of proteins from polyacrylamide gels by nano electrospray mass spectrometry. Nature 379:466-469.

Wu J, Matunis MJ, Kraemer D, Blobel G, Coutavas E. 1995. Nup358, a cytoplasmically exposed nucleoporin with peptide repeats, RanGTP binding sites, zinc fingers, a cyclophilin A homologous domain, a leucine-rich region. J Biol Chem 270:14209-14213.

Yokoyama N, Hayashi N, Seki T, Panté N, Ohba T, Nishii K, Kuma K, Hayashida T, Miyata T, Aebi U, Fukui M, Nishimoto T. 1995. RanBP2, a giant nuclear pore protein which binds Ran/TC4. Nature 376:184-188.

Zolotukhin AS, Felber BK. 1997. Mutations in the nuclear export signal of human Ran-binding protein RanBP1 block the Revmediated posttranscriptional regulation of human immunodeficiency virus type 1. J Biol Chem 272:11356-11360.

Zolotukhin AS, Felber B. 1999. Nucleoporins Nup98 and Nup214 participate in nuclear export of Human Immunodeficiency Virus Type 1 Rev. J Virol 73:120-127. 